\title{
Anais do X Encontro de
}

\section{Ligas Acadêmicas da Univaço 2021}

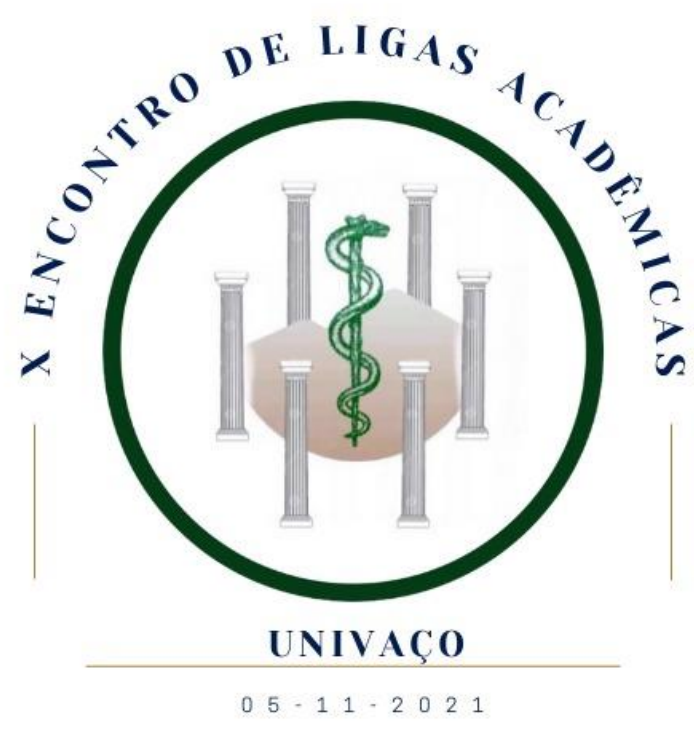

\section{Apoio:}

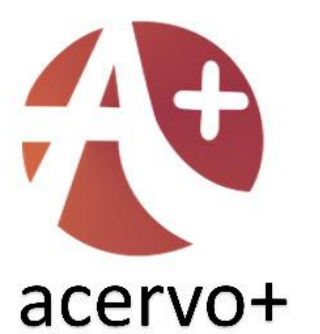

Eventos

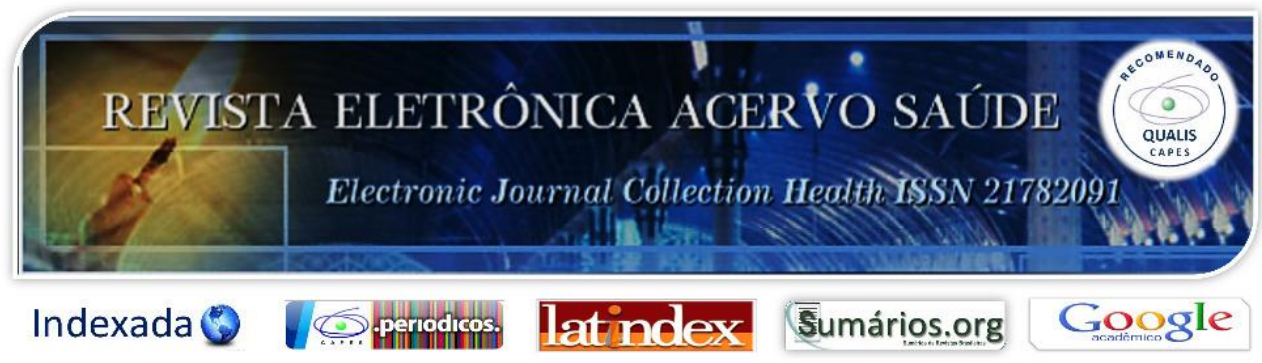




\section{SUMÁRIO}

SOBRE O EVENTO

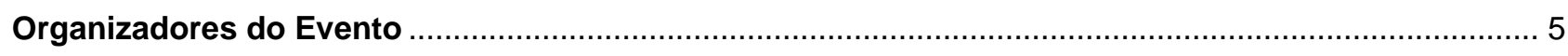

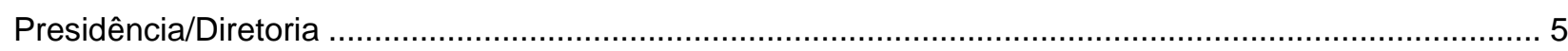

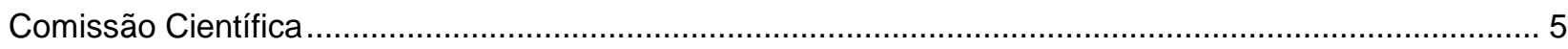

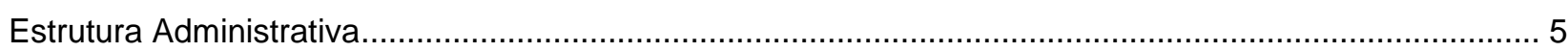

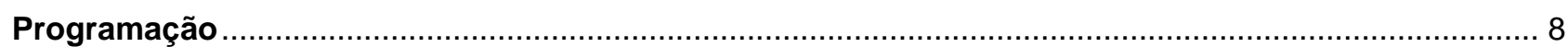

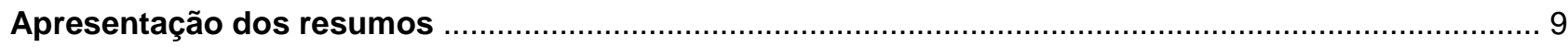

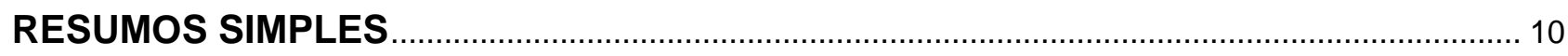

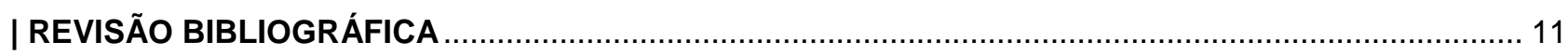

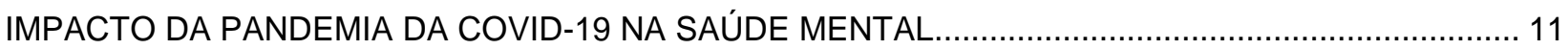

OS PRINCIPAIS TRANSTORNOS MENTAIS E SEU IMPACTO NA QUALIDADE DE VIDA DOS IDOSOS

COVID-19: A INFLUÊNCIA DA MICROBIOTA INTESTINAL NO CURSO DA INFECÇÃO ...................... 15

CORREÇÃO ROBÓTICA DE HÉRNIA VENTRAL: UMA REVISÃO BIBLIOGRÁFICA............................ 17

CUIDADOS PALIATIVOS NO CONTEXTO DA PANDEMIA PELA COVID-19 ....................................... 19

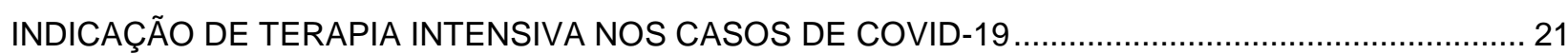

O PROCESSO DE HORMONIZAÇÃO EM TRANSEXUAIS: RISCO DE TROMBOEMBOLISMO VENOSO

A INSUFICIÊNCIA PLACENTÁRIA COMO PRINCIPAL CAUSA DE RESTRIÇÃO DE CRESCIMENTO

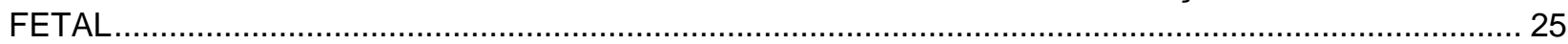

TRANSEXUALIZAÇÃO: REVISÃO DE LITERATURA FOCADA NA PSIQUIATRIA DO PROCESSO...... 27

PERFIL EPIDEMIOLÓGICO DAS UTIS NO BRASIL ..................................................................... 29

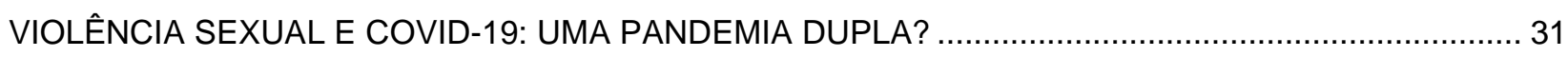

OBESIDADE INFANTIL: QUAIS FATORES TÊM LEVADO O AUMENTO DE PESO ENTRE CRIANÇAS

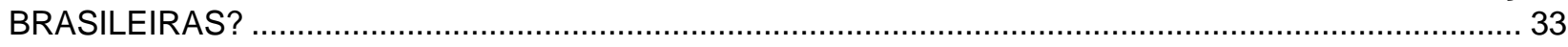

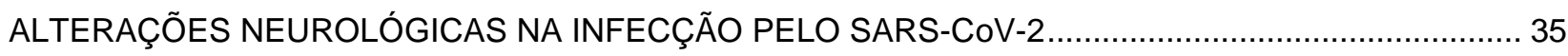

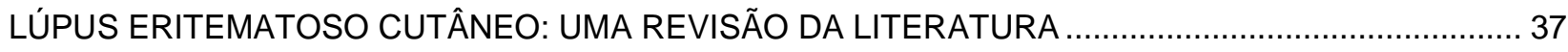

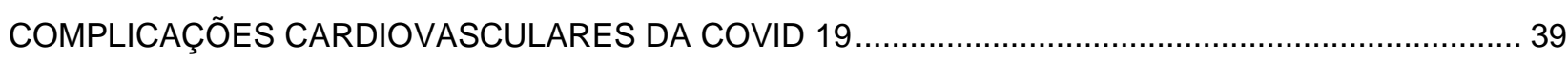

QUEDAS EM IDOSOS E O PAPEL DA ATENÇÃO PRIMÁRIA À SAÚDE …........................................ 41

PROPOSTA DE IMPLANTAÇÃO DE JOGOS PARA O APRENDIZADO DO INGLÊS MÉDICO: SERIA ESSA UMA SOLUÇÃO PARA APROXIMAR O ESTUDANTE DA LÍNGUA INGLESA? ......................... 43

ABORDAGEM DA DISQUESIA DO LACTENTE: REVISÃO DE LITERATURA ..................................... 45

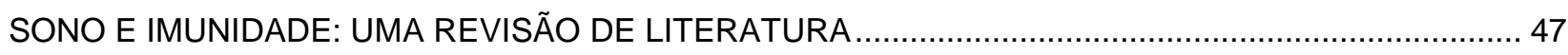

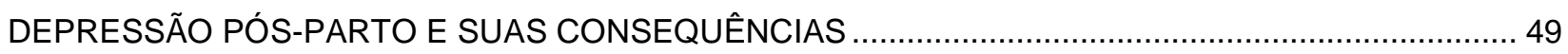

SÍNDROME DE BLAU: REVISÃO DE LITERATURA ................................................................. 51 
O PAPEL DA ATIVIDADE FÍSICA NO TRATAMENTO DE TRANSTORNOS DE ANSIEDADE 53 OS CRITÉRIOS DE INDICAÇÃO E AS COMPLICAÇÕES DA TIREOIDECTOMIA ENDOSCÓPICA TRANSORAL. 55

ENCEFALITE HERPÉTICA: UMA REVISÃO INTEGRATIVA 57 DIETA CETOGÊNICA COMO TRATAMENTO PARA EPILEPSIA RESISTENTE A MEDICAMENTOS: UMA REVISÃO DE LITERATURA 59

| RELATO DE EXPERIÊNCIA 61

A DISSEMINAÇÃO DE CONHECIMENTO INTERNACIONAL AO CORPO ACADÊMICO EM PARCERIA COM A LIGA DE INGLÊS MÉDICO: UM RELATO DE EXPERIÊNCIA 61 IMPLANTAÇÃO DE UM APLICATIVO PARA MONITORAMENTO E BARREIRA SANITÁRIA PARA COVID-19: UM RELATO DE EXPERIÊNCIA........ 63 


\section{SOBRE O EVENTO}

O X Encontro de Ligas Acadêmicas da Univaço - 2021 é um evento idealizado pelas Ligas Acadêmicas da União Educacional do Vale do Aço (Univaço) com apoio da instituição, com o objetivo de promover integração entre elas, disseminando o conhecimento, estimulando o interesse e o engajamento em relação à pesquisa e visando a integração cultural e científica.

O evento aconteceu no dia 05 de novembro de 2021, contou com a abordagem de diversas temáticas da Medicina, através de palestras e oficinas práticas, funcionando em modelo híbrido, com uma parte de forma presencial e a outra através de plataformas online.

Acreditamos que o evento possibilitou aos acadêmicos o desenvolvimento do potencial científico e das habilidades médicas, além de permitir a submissão de trabalhos que foram apresentados de forma oral e em formato de pôster. 


\section{Organizadores do Evento}

\section{Presidência/Diretoria}

Me. Fabiano Moreira Silva

Ana Paula de Castro Gomes Gervásio

Guilherme Simeão Casati

lara Gomes Breder

Júlia Araújo Ladeira

\section{Comissão Científica}

Aiane Xavier Felipe Batalha

Ana Carolina Vale Campos Lisbôa

Analina Furtado Valadão

Catarina Amorim Baccarini Pires

Fabiano Moreira Silva

Leonardo de Araújo Lopes

Trycia Martins Salviano Alves

\section{Estrutura Administrativa}

Liga Acadêmica de Anatomia Clínica

Presidente: Edna Mariana de Souza Costa

Vice-Presidente: Juliana Fernandes Saar Garcia

Liga Acadêmica de Gestão e Empreendedorismo Médico

Presidente: Laura Rodrigues Silva

Vice-Presidente: Lívia Pêpe Leão da Rocha

\section{Liga Acadêmica de Psiquiatria}

Presidente: Luiza Giordani Mileo

Vice-Presidente: Nicolas Leite Rodrigues Correa 
Liga Acadêmica de Pediatria e Neonatologia

Presidente: Christiana Assis de Souza

Vice-Presidente: Thalita Maria Coelho Cherobim Garonci

Liga Acadêmica de Prática Cirúrgica em Urgência e Emergência

Presidente: Lara Calhau Rebouças

Liga Acadêmica de Medicina de Família e Comunidade

Presidente: Ana Angélica Silva de Resende

Vice-Presidente: Mariana Nazareth Prado

Liga Acadêmica de Tanatologia e Cuidados Paliativos

Presidente: Bruna Luísa Damiani

Vice-Presidente: Nicolas Alvarenga Silva

Liga Acadêmica de Neurologia e Neurociência

Presidente: Paula Moreira Sena

Vice-Presidente: Henrique Brandião Costa

Liga Acadêmica de Ginecologia e Obstetrícia

Presidente: Sara Almeida Moreira

Vice-Presidente: Camila Moreira Costa

Liga Acadêmica de Dermatologia

Presidente: Pedro Duarte Moreira Andrade

Vice-Presidente: Maria Laura Lazaroto

Liga Acadêmica de Geriatria e Gerontologia

Presidente: Cássio Henrique Alves Póvoas

Vice-Presidente: Brenda Anacleto De Miranda 
Liga Acadêmica de Cardiologia

Presidente: Letícia Ferreira Jordão

Vice-Presidente: Jyennyffer Barral Rodrigues

Liga Acadêmica de Medicina Intensiva

Presidente: Márcio Henrique Moreira

Vice-Presidente: Gabriel Calafange Cunha

Liga Acadêmica de Saúde Sexual

Presidente: Isabela Guedes Paiva

Vice-Presidente: Ícaro Silva Magalhães

Liga Acadêmica de Aprendizado Baseado em Casos Clínicos

Presidente: Camilla de Freitas Maziero

Vice-Presidente: Rayenne Rodrigues Nascente

Liga Acadêmica de Imunologia

Presidente: Ana Luiza Andrade Fantoni

Vice-Presidente: Luan Jose Martins Pereira

Liga Acadêmica de Inglês Médico

Presidente: Júlia Araújo Ladeira

Vice-Presidente: Gabriela Roque Pereira 


\section{Programação}

\begin{tabular}{|c|c|c|}
\hline \multicolumn{3}{|c|}{ 05/11/2021 } \\
\hline Horário & Evento & \\
\hline 07:00 - 08:00 & Cerimônia de abertura & Univaço \\
\hline 08:00 - 09:00 & Salas de workshop e apresentação de pôster & Univaço \\
\hline 09:00 - 10:00 & Salas de workshop e apresentação de pôster & Univaço \\
\hline $10: 00-11: 00$ & Salas de workshop e apresentação de pôster & Univaço \\
\hline $11: 00-13: 30$ & Intervalo & \\
\hline $13: 30-14: 30$ & Salas de workshop e apresentação de pôster & Univaço \\
\hline $14: 30-15: 30$ & Salas de workshop e apresentação de pôster & Univaço \\
\hline $15: 30-16: 30$ & Salas de workshop e apresentação de pôster & Univaço \\
\hline $16: 30-18: 00$ & Intervalo & \\
\hline $18: 00-19: 00$ & Salas de apresentação oral de trabalhos & Plataforma online \\
\hline 19:00 - 20:30 & Palestra & Plataforma online \\
\hline $20: 30-21: 00$ & Cerimônia de encerramento & Plataforma online \\
\hline
\end{tabular}




\section{Apresentação dos resumos}

Prezados leitores, nesta publicação, se encontram os resumos apresentados no $X$ Encontro de Ligas Acadêmicas da Univaço - 2021, realizado no dia 05 de novembro de 2021.

Foram aprovados 27 resumos simples, sendo 25 na forma de revisão bibliográfica e 2 no formato de relato de experiência, analisados pela comissão científica do evento e pelo editor da Revista Eletrônica Acervo Saúde, estando de acordo com as normas e critérios de avaliação do periódico.

Os trabalhos selecionados apresentam temas relevantes para a formação e para a prática da medicina. Além disso, contribuem de forma grandiosa para o sucesso do nosso evento, trazendo temas que instigam o raciocínio clínico e promovem o pensamento crítico.

A qualidade dos trabalhos enriquece a experiência do público e consolida para os acadêmicos a importância da pesquisa científica. A partir dessa experiência prática, é possível contribuir com o fomento da produção científica entre os graduandos de medicina, na esperança de que oportunidades como essa, se tornem mais comuns.

\section{Comissão Científica do Evento}




\section{RESUMOS SIMPLES}

Revisão Bibliográfica: 25 resumos

Relato de Experiência: 2 resumos 


\section{| REVISÃO BIBLIOGRÁFICA}

RESUMO SIMPLES: Revisão Bibliográfica

IMPACTO DA PANDEMIA DA COVID-19 NA SAÚDE MENTAL

Autor/coautores: Amanda Maciel Carvalho, Ana Paula de Castro Gomes Gervásio, Laura Maria Pouzas Torres, Nícolas Leite Rodrigues Corrêa, Melissa Heringer Chamon Barros Quintão.

Instituição: União Educacional do Vale do Aço (UNIVAÇO), Ipatinga - MG.

Palavras-chave: COVID-19, Saúde mental, Psiquiatria.

\section{INTRODUÇÃO}

A Organização Mundial de Saúde (OMS) declarou, no dia 30 de janeiro de 2020, o surto da COVID-19, causada pelo vírus SARS-CoV-2 (HOLSHUE ML, et al., 2020). Dando início a uma difícil fase para a saúde e para a adaptação da sociedade frente à pandemia. A COVID-19 também gerou reflexos na saúde mental da população, em virtude do medo da nova infecção e das incertezas no cenário socioeconômico, provocando um aumento das afecções psiquiátricas relacionadas à fração do povo que está mais ameaçada pelo vírus, aumentando ainda mais os desafios para a saúde global (HOSSAIN M, et al., 2020).

\section{OBJETIVO}

Revisar a literatura científica existente, a fim de investigar e discutir o impacto da pandemia da COVID-19 na saúde mental, assim como correlacionar os principais fatores envolvidos no adoecimento mental e os principais grupos acometidos.

\section{REVISÃO BIBLIOGRÁFICA}

Embora ainda haja limitação de estudos acerca das consequências à saúde mental, associadas à COVID19, os resultados encontrados apresentam diversos fatores envolvidos no adoecimento mental durante a atual pandemia, principalmente: aumento exponencial do número de casos e de óbitos; incertezas socioeconômicas; quarentena e lockdown mandatórios; isolamento; medo; ausência de tratamento efetivo; medidas de controle de transmissão inadequadas; dificuldade vacinal; bombardeio de informações; comorbidades físicas e psiquiátricas e estresse (HOSSAIN M, et al., 2020; SERAFINI G, et al., 2020).

Os grupos que apresentaram maior impacto negativo sobre a saúde mental foram os idosos, os profissionais de saúde e os indivíduos com transtornos psiquiátricos prévios (HOSSAIN M, et al., 2020). Historicamente, crises econômicas e pandemias resultaram em depressão; transtornos ansiosos e somatoformes; abuso de substâncias; aumento de tendências suicidas; distúrbios do sono e estresse póstraumático, dentre outras comorbidades psiquiátricas. No entanto, os estudos em relação a COVID-19 ainda são muito limitados, devido a dificuldade de selecionar uma amostra que possa refletir o padrão da população geral e da realização de um estudo prospectivo (BHATTACHARJEE B e ACHARYA T, 2020).

\section{CONSIDERAÇÕES FINAIS}

A pandemia ocasionada pela COVID-19 apresenta consequências diretas e indiretas sobre a saúde mental do indivíduo, afetando, principalmente, os profissionais da saúde e os idosos, resultando no surgimento de diversas condições debilitantes relacionadas à saúde mental individual e coletiva. Dessa forma, é de 
emergente necessidade, a adoção de intervenções multidisciplinares para o enfrentamento dos problemas psicossociais e para a promoção da saúde mental frente à atual pandemia.

\section{REFERÊNCIAS}

1. BHATTACHARJEE B, ACHARYA T. The COVID-19 Pandemic and its Effect on Mental Health in USA - A Review with Some Coping Strategies. Psychiatric Quarterly, 2020; 91(4):1135-1145.

2. HOLSHUE ML, et al. First case of 2019 novel coronavirus in the United States. New England Journal of Medicine, 2020; 382(10): 929-936.

3. HOSSAIN M, et al. Epidemiology of mental health problems in COVID-19: a review. F1000Research, 2020; 9: 636 .

4. SERAFINI G, et al. The psychological impact of COVID-19 on the mental health in the general population. QJM: An International Journal of Medicine, 2020; 113(8): 529-535. 
RESUMO SIMPLES: Revisão Bibliográfica

\section{OS PRINCIPAIS TRANSTORNOS MENTAIS E SEU IMPACTO NA QUALIDADE DE VIDA DOS IDOSOS}

Autor/coautores: Vitória Barreto Salomão, Brenda Anacleto de Miranda, Amy Ferraz Pizzol, Cássio Henrique Alves Póvoas, Sávio Francisco Ulhôa.

Instituição: União Educacional do Vale do Aço (UNIVAÇO), Ipatinga - MG.

Palavras-chave: Idosos, Doenças mentais, Qualidade de vida.

\section{INTRODUÇÃO}

O envelhecimento populacional é um fenômeno inevitável com consequências sociais, econômicas e biológicas que culminam na mudança do perfil de saúde da população. Assim, maior atenção deve ser destinada aos transtornos que acometem esta faixa etária, sobretudo às doenças mentais, que muitas vezes recebem menor atenção em relação a saúde física, mas são essenciais para o bem-estar geral dos indivíduos na sociedade (ARSLANOGLOU E, et al., 2019). Ao longo do tempo, os transtornos causados pelo envelhecimento, podem causar ou agravar doenças mentais, como depressão, delirium e quadros demenciais com alteração de comportamento, que são alguns dos transtornos mais comuns na população idosa (TOOTS A, et al., 2017).

\section{OBJETIVO}

Revisar a literatura científica sobre os principais transtornos mentais que acometem a população idosa, bem como o estabelecimento de intervenções precoces e individualizadas, que promovam atenção integral à saúde e, assim, proporcionam uma melhora na qualidade de vida dos idosos.

\section{REVISÃO BIBLIOGRÁFICA}

Entre as doenças mentais, a depressão é uma das principais causas de sofrimento e incapacidade, costuma ser distinta nos idosos, geralmente está relacionada a outras comorbidades, com presença de sintomas físicos, riscos para a função executiva e comprometimento cognitivo, que podem levar ao desenvolvimento ou piora dos quadros demenciais com o consequente aumento da mortalidade (KOK RM e REYNOLDS CF, 2017).

A demência por sua vez, é uma das principais causas de deficiência e dependência de pessoas idosas em todo o mundo, se manifesta com deficiências de memória, linguagem ou função executiva, sendo a Doença de Alzheimer mais comumente apresentada (HENSKENS M, et al., 2018).

Outra síndrome encontrada em idosos é o delirium, caracterizado por mudanças drásticas na atenção, consciência e cognição, causado por doenças neuropsiquiátricas comuns e graves, geralmente não é detectado devido a existência ou não de uma causa base (MARCANTONIO ER, 2017). Portanto, as doenças mentais podem afetar a qualidade de vida do idoso e seus familiares, com o comprometimento cognitivo, levando à perda substancial da sua independência (WILSON JE, et al., 2020).

\section{CONSIDERAÇÕES FINAIS}

Dessa forma, é notável o tamanho impacto que doenças mentais causam na qualidade de vida dos nossos idosos, visto que além de consequências psicológicas, as mesmas podem trazer prejuízos motores, sensoriais, emocionais e comportamentais, interferindo diretamente no processo de envelhecimento saudável. Desse modo, torna-se necessária uma maior atenção a qualquer sinal de alteração mental, buscando auxílio e tratamento adequado. 


\section{REFERÊNCIAS}

1. ARSLANOGLOU E, et al. Negative emotions and the course of depression during psychotherapy in suicidal older adults with depression and cognitive impairment. The American Journal of Geriatric Psychiatry, 2019; 27(12): 1287-1295.

2. HENSKENS M, et al. The effects of movement stimulation on activities of daily living performance and quality of life in nursing home residents with dementia: a randomized controlled trial. Clinical interventions in aging, 2018; 13: 805.

3. KOK RM, REYNOLDS CF. Management of depression in older adults: a review. Jama, 2017; 317(20): 2114-2122.

4. MARCANTONIO ER. Delirium in hospitalized older adults. New England Journal of Medicine, 2017; 377(15): 1456-1466.

5. TOOTS A, et al. Effects of exercise on cognitive function in older people with dementia: a randomized controlled trial. Journal of Alzheimer's Disease, 2017; 60(1): 323-332.

6. WILSON JE, et al. Delirium. Nature Reviews Disease Primers, 2020; 6(1): 90. 
RESUMO SIMPLES: Revisão Bibliográfica

\section{COVID-19: A INFLUÊNCIA DA MICROBIOTA INTESTINAL NO CURSO DA INFECÇÃO}

Autor/coautores: Jéssica Lorena Pereira, Nicole Ranne Oliveira Guimarães, Sávio Souza de Oliveira, Giani Martins Garcia.

Instituição: União Educacional do Vale do Aço (UNIVAÇO), Ipatinga - MG.

Palavras-chave: COVID-19, Imunidade, Microbiota gastrointestinal.

\section{INTRODUÇÃO}

A microbiota intestinal saudável está intimamente ligada à saúde pulmonar e sistêmica via regulação imunológica (HE LH, et al., 2020). Além dos sintomas respiratórios, a infecção por COVID-19 ocasionou sintomas gastrointestinais levando a estudos sobre a relação da microbiota com o prognóstico e potencial estratégia de prevenção e tratamento da infecção. Em uma metanálise envolvendo 4.243 pacientes, a prevalência dos sintomas gastrointestinais foi de 17,6\% (CHEUNG KS, et al., 2020). Dados sugerem que a microbiota intestinal pode ser mediadora da resposta imune anormal em pacientes infectados e suas alterações foram associadas à suscetibilidade e gravidade (HE LH, et al., 2020; ALMEIDA JFM e CHEHTER EZ, 2020).

\section{OBJETIVO}

Buscar referências na literatura que abordem os fatores relacionados à microbiota intestinal que possam interferir no curso imunológico e prognóstico da infecção pela COVID-19, utilizando estudos dos últimos dois anos das plataformas PubMed e Scielo.

\section{REVISÃO BIBLIOGRÁFICA}

A microbiota intestinal produz metabólitos, como ácidos graxos de cadeia curta (AGCC), atuantes como barreira imunológica, aumentam a função das células T reguladoras, Th1 e Th17, impedindo inflamações exacerbadas (HE LH, et al., 2020). Amostras fecais de pacientes com sintomas leves ou assintomáticos tiveram aumento de bactérias produtoras de AGCC (ZUO T, et al., 2021).

O vírus da COVID-19 utiliza a enzima conversora de angiotensina 2 presentes no pulmão e intestino para entrar nas células. Este receptor regula a microbiota intestinal e seu bloqueio gera menor produção de peptídeos antimicrobianos. A disbiose encontrada foi associada a maior susceptibilidade e gravidade da infecção, com internação em unidade de tratamento intensivo, em relação aos pacientes sem sintomas gastrointestinais (6,67\% versus 2,08\%, respectivamente) (ALMEIDA JFM e CHEHTER EZ, 2020).

Evidências indiretas indicam que probióticos contendo Lactobacilos e bifidobactérias podem otimizar a resposta ao COVID-19, entretanto a utilização indiscriminada de probióticos como controle da infecção em pacientes ainda não é comprovada (MAK JWY, et al., 2020).

\section{CONSIDERAÇÕES FINAIS}

À vista dos dados revisados, os sintomas gastrointestinais em pacientes contaminados não devem ser negligenciados, já que podem preceder agravamento. Assim, a influência da microbiota e o uso de probióticos precisam ser mais esclarecidos. Nesse viés, deve-se reforçar os benefícios da manutenção de bons hábitos de vida como atuante no controle de doenças e fortalecimento das reações imunológicas. 


\section{REFERÊNCIAS}

1. ALMEIDA JFM, CHEHTER EZ. COVID-19 and the gastrointestinal tract: what do we already know? Einstein, 2020; 18: 1-14.

2. CHEUNG KS, et al. Gastrointestinal manifestations of SARS-CoV-2 infection and virus load in fecal samples from a Hong Kong cohort: systematic review and meta-analysis. Gatroenterology, 2020; 159(1): 81-95.

3. HE LH, et al. Intestinal flora as a potential strategy to fight SARS-CoV-2 infection. Frontiers in Microbiology, 2020; 11: 1388.

4. MAK JWY, et al. Probiotics and COVID-19: one size does not fit all. Lancet Gastroenterol Hepatol, 2020; 5(7): 644-645.

5. ZUO T, et al. Depicting SARS-CoV-2 faecal viral activity in association with gut microbiota composition in patients with COVID-19. Gut, 2021; 70: 276-284. 
RESUMO SIMPLES: Revisão Bibliográfica

\section{CORREÇÃO ROBÓTICA DE HÉRNIA VENTRAL: UMA REVISÃO BIBLIOGRÁFICA}

Autor/coautores: Naiara Fernandes Pimentel, Camila Baquieti Carminate, Sarah Karollyne Ferreira Taxa, Magid José Mendes Lauar.

Instituição: União Educacional do Vale do Aço (UNIVAÇO), Ipatinga - MG.

Palavras-chave: Cirurgia, Robótica, Hérnia ventral.

\section{INTRODUÇÃO}

A robotização de procedimentos médicos tem sido recorrente e com os avanços tecnológicos tais mudanças são inevitáveis. Entre as áreas submetidas a modernização de procedimentos, destaca-se a cirurgia geral, na qual observa-se a correção de hérnia ventral (OLAVARRIA OA, et al., 2020). Até o momento, sabe-se que as técnicas mais usadas nesse procedimento são as cirurgias abertas e a laparoscopia, porém a aderência da correção de hérnia ventral robótica é crescente. Com o aumento das hérnias ventrais complexas, somado às outras limitações da laparoscopia e a busca pela redução de hérnias reincidentes, evidencia-se a necessidade de ampliar os estudos dos reparos robóticos (NGUYEN B, et al., 2021).

\section{OBJETIVO}

Realizar uma revisão bibliográfica da literatura científica dos últimos cinco anos, de modo sistemático, acerca da correção robótica de hérnia ventral, destacando as vantagens e desvantagens com a utilização desse método de correção cirúrgica.

\section{REVISÃO BIBLIOGRÁFICA}

Inicialmente, as principais desvantagens descritas sobre a abordagem robótica envolvem o alto custo e aumento do tempo de duração da cirurgia. Também, foi demonstrado não haver diferença significativa no período de 90 dias pós-operatório entre a operação cirúrgica robótica e laparoscópica (OLAVARRIA OA, et al., 2020). Entretanto, diversas vantagens da cirurgia robótica comparada à laparoscopia foram encontradas, como visão tridimensional, imagem estabilizada, escassez de tremores e diversas formas de abordagem de ângulos (NGUYEN B, et al., 2021).

Também, foram relatados benefícios aos próprios cirurgiões, por exemplo, diminuição no estresse físico e intelectual, podendo, inclusive, a cirurgia robótica estender a carreira de um cirurgião, uma vez que a tecnologia robótica reduz a incidência de dor crônica que, frequentemente, atinge os cirurgiões laparoscópicos (SÁNCHEZ A, et al., 2018). Por fim, percebeu-se um aumento do número de correção de hérnias minimamente invasivas (DONKOR C, et al., 2017), bem como a vantagem de dominar a dissecção da parede abdominal anterior, cujo sucesso na laparoscopia só era possível com cirurgiões experientes (MORRELL ALG, et al., 2020).

\section{CONSIDERAÇÕES FINAIS}

A partir dos dados existentes na literatura sobre o tema, foi possível compreender que a cirurgia robótica apresenta grandes vantagens como a apresentação estética, utilização de vias minimamente invasivas e sua efetividade em manter a integridade da parede abdominal. No entanto, mais estudos são necessários para verificar a utilização de ferramentas que auxiliam na orientação anatômica para uma melhor visão da parede abdominal e evitar complicações. 


\section{REFERÊNCIAS}

1. CÂMARA ERZ, et al. Facilitando a reconstrução minimamente invasiva da parede abdominal: aplicação do sistema robótico na correção de hérnia paraestomal. Relatos Casos Cir., 2017; (2): 1-4.

2. DONKOR C, et al. Current perspectives in robotic hernia repair. Robotic surgery, 2017; 4: 57-67.

3. MORRELL ALG, et al. Hérnias ventrais por acesso lateral totalmente extraperitoneal robótico (eTEP): dez etapas essenciais na padronização técnica. Revista do Colégio Brasileiro de Cirurgiões, 2020; 47: e20202622.

4. NGUYEN B, et al. Comparisons of abdominal wall reconstruction for ventral hernia repairs, open versus robotic. Scientific Reports, 2021; 11(1): e8086.

5. OLAVARRIA OA, et al. Robotic versus laparoscopic ventral hernia repair: multicenter, blinded randomized controlled trial. BMJ (Clinical research ed.), 2020; 370: e2457.

6. SÁNCHEZ A, et al. Robot-assisted surgery, and incisional hernia: a comparative study of ergonomics in a training model. Journal of Robotic Surgery, 2018; 12(3): 523-527. 
RESUMO SIMPLES: Revisão Bibliográfica

\section{CUIDADOS PALIATIVOS NO CONTEXTO DA PANDEMIA PELA COVID-19}

Autor/coautores: Maressa Precioso Verdin, Bruna Luísa Damiani, Isabella Ferreira Dias, Nicolas Alvarenga Silva, Leonardo Ennes Carrilho.

Instituição: União Educacional do Vale do Aço (UNIVAÇO), Ipatinga - MG.

Palavras-chave: Cuidados paliativos, Pandemia, Covid-19.

\section{INTRODUÇÃO}

O estado de pandemia pela Covid-19, decretado pela Organização Mundial da Saúde (OMS), expôs o óbice em termos de bens disponíveis, organização de serviços de saúde e equipes de profissionais aptos para atuação nesse contexto, sobretudo devido ao rápido aumento do número de infectados e de óbitos em vários países. Assim, os princípios dos cuidados paliativos podem instrumentalizar os profissionais de saúde e ganhar destaque, por intervenção de equipe multidisciplinar, objetivando reduzir e prevenir o sofrimento, aprimorar a qualidade de vida tanto dos indivíduos com morbidades graves, quanto de seus familiares (FLORÊNCIO RS, et al., 2020; TRITANY EF, et al., 2020).

\section{OBJETIVO}

Revisar a literatura acerca da importância dos cuidados paliativos como estratégia para enfrentamento à crescente demanda pelos serviços de saúde, e para minimizar os sofrimentos físicos e psíquicos gerados, decorrentes da pandemia pela Covid-19.

\section{REVISÃO BIBLIOGRÁFICA}

A Covid-19 trouxe desafios às esferas políticas, sociais, econômicas e, principalmente à saúde. Nesse contexto, os cuidados paliativos são abordagens executadas por uma equipe multiprofissional que abrangem os processos dinâmicos da terminalidade da vida, progressão de doenças crônicas e amparo ao luto. Logo, visam a promoção do conforto por meio da amenização da dor física, psíquica, social e espiritual tanto no paciente quanto nos indivíduos vinculados a ele (FLORÊNCIO RS, et al., 2020; CREPALDI MA, et al., 2020).

Uma estratégia para minimizar esses impactos da pandemia pode ser a disseminação e aplicabilidade transversal dos princípios dos cuidados paliativos nos diversos níveis da rede de atenção à saúde, por meio de financiamento e execução de projetos de educação permanente e continuada desses trabalhadores, além da inserção do assunto nas dimensões teórica e prática em currículos de graduação em saúde (TRITANY EF, et al., 2020).

\section{CONSIDERAÇÕES FINAIS}

Quando os cuidados curativos não produzem o resultado esperado, a adoção dos cuidados paliativos está indicada. Em geral, a adoção desses princípios propicia dignidade e alívio do sofrimento, principalmente em pacientes graves, em seus familiares e conforta os profissionais de saúde. Com o advento da pandemia pela Covid-19, fica evidente a necessidade de medidas que possam disseminar e democratizar o acesso a essa estratégia.

\section{REFERÊNCIAS}


1. CREPALDI MA, et al. Terminalidade, morte e luto na pandemia de COVID-19: demandas psicológicas emergentes e implicações práticas. Estudo de Psicologia (Campinas), 2020; 37: e200090.

2. FLORÉNCIO RS, et al. Cuidados paliativos no contexto da pandemia de COVID-19: desafios e contribuições. Acta Paulista de Enfermagem, 2020; 33: 1-9.

3. ORGANIZAÇÃO MUNDIAL DA SAÚDE (OMS). Declaração do Diretor-Geral da OMS sobre o Comitê de Emergência do RSI sobre Novos Coronavírus (2019-nCoV). Disponível em: https://www.who.int/directorgeneral/speeches/detail/who-director-general-s-statement-on-ihr-emergency-committee-on-novelcoronavirus-(2019-ncov). Acessado em: 15 de agosto de 2021.

4. TRITANY EF, et al. Fortalecer os Cuidados Paliativos durante a pandemia de Covid-19. Interface (Botucatu), 2021; 25: e200397. 
RESUMO SIMPLES: Revisão Bibliográfica

\section{INDICAÇÃO DE TERAPIA INTENSIVA NOS CASOS DE COVID-19}

Autor/coautores: Ivy Letícia Brandião Costa, Lara de Sousa Nunes Gonçalves, Juliana Cesconetto, Maria Clara Matos Morais, Danilo Ribeiro de Miranda.

Instituição: União Educacional do Vale do Aço (UNIVAÇO), Ipatinga - MG.

Palavras-chave: Terapia intensiva, COVID-19, UTI.

\section{INTRODUÇÃO}

No ano de 2019, detectou-se na China a doença por Coronavírus (COVID-19), declarando-se posteriormente a pandemia, devido à disseminação mundial. Consequentemente, a demanda pelos serviços e pela ampliação das Unidades de Terapia Intensiva (UTI) tornou-se imprescindível (MOREIRA RS, 2020). Nesse sentido, a admissão nas UTIs deve priorizar aqueles que necessitam de intervenções de suporte à vida, com alta probabilidade de recuperação e sem nenhuma limitação de suporte terapêutico e, posteriormente, aqueles que precisam de monitorização intensiva. Ademais, a análise individual, técnica e ética do paciente com COVID-19 faz-se necessária (BRASIL, 2016).

\section{OBJETIVO}

Abordar as principais indicações de terapia intensiva no paciente com COVID-19, elucidando os sinais de alarme e critérios para identificação do paciente elegível para internação, de forma a auxiliar os médicos na decisão e manejo das formas graves da doença.

\section{REVISÃO BIBLIOGRÁFICA}

Com a grande demanda gerada pelo COVID-19, foi necessário estabelecer critérios para as indicações dos pacientes infectados pela doença à Terapia Intensiva (TI). Corroborando com a Resolução № 2.156/2016 do Conselho Federal de Medicina (CFM), para admissão à UTI, é necessário que o paciente esteja em uma situação de instabilidade clínica, sendo necessário determinar cinco níveis de prioridade para internação, como intervenções de suporte à vida, com alta probabilidade de recuperação até aos pacientes terminais (MOREIRA RS, 2020).

Logo, a decisão sobre indicar o paciente à TI está diretamente relacionada às questões éticas e técnicas. Sob a perspectiva ética, é prescrito ao profissional qualquer tipo de discriminação, reconhecendo que não há vidas com menor valor que outras. Já em relação a técnica, é preciso analisar os fatores agravantes, como idade e determinadas comorbidades anteriores. Apesar de tais prioridades, há situações clínicas que são mandatórias para o encaminhamento à UTI, como insuficiência respiratória aguda com necessidade de ventilação mecânica; sepse; instabilidade hemodinâmica; necessidade de vasopressores e disfunção orgânica (BRASIL, 2020).

\section{CONSIDERAÇÕES FINAIS}

Em frente à crise sanitária da COVID-19, a maioria dos sistemas de saúde do Brasil, tiveram que se adequar com a grande demanda de pacientes e com poucos recursos médicos assistenciais. Portanto, é importante que os médicos saibam quais pacientes são elegíveis para terapia intensiva, de forma a amenizar o impacto na saúde da população e no número de leitos das UTIs. 


\section{REFERÊNCIAS}

1. BRASIL. Associação de Medicina Intensiva Brasileira. Protocolo AMIB de alocação de recursos em esgotamento durante a pandemia por COVID-19. 2020. Disponível em: https://www.mpma.mp.br/arquivos/CAOPSAUDE/Protocolo_AMIB_de_alocacao_de_recursos_em_esgot amento_durante_a_pandemia_por_COVID-19.pdf. Acessado em: 22 de julho de 2021.

2. BRASIL. Conselho Federal de Medicina. Resolução do CFM № 2.156/2016. 2016. Disponível em: https://sistemas.cfm.org.br/normas/visualizar/resolucoes/BR/2016/2156. Acessado em: 22 de julho de 2021.

3. MOREIRA RS. COVID-19: unidades de terapia intensiva, ventiladores mecânicos e perfis latentes de mortalidade associados à letalidade no Brasil. Cadernos de Saúde Pública, 2020; 36(5):e00080020. 
RESUMO SIMPLES: Revisão Bibliográfica

\section{O PROCESSO DE HORMONIZAÇÃO EM TRANSEXUAIS: RISCO DE TROMBOEMBOLISMO VENOSO}

Autor/coautores: José Helvécio Kalil, André Rhodes Neves, Jênifer Bicalho de Assis, Maria Luiza Prata Borghi, Patrícia Coelho Ferreira.

Instituição: União Educacional do Vale do Aço (UNIVAÇO), Ipatinga - MG.

Palavras-chave: Transexuais, Terapia de reposição hormonal, Trombose.

\section{INTRODUÇÃO}

O transexual não se identifica com o sexo biológico, possuindo desejo de adequar seu corpo por meio da terapia hormonal, pois sente-se preso no corpo errado (CAMPANA GA, et al., 2018). Apesar da terapia hormonal permitir o desenvolvimento das características sexuais secundárias almejadas, o uso de esteroides sexuais pode ocasionar agravos à saúde, principalmente elevando o risco tromboembólico. 0 tromboembolismo venoso (TEV) consiste na obstrução do lúmen do vaso sanguíneo por meio de trombos constituídos de fibrina e plaquetas, sendo os membros inferiores os mais acometidos (CARMO GM, et al., 2020).

\section{OBJETIVO}

Revisar a literatura científica a respeito da terapia de substituição hormonal, no processo de transexualização, com enfoque na análise do risco de tromboembolismo venoso, que pode acarretar insuficiência venosa crônica e embolia pulmonar.

\section{REVISÃO BIBLIOGRÁFICA}

A terapia hormonal (TH) para o processo de transexualização consiste na administração de hormônios, estrógenos ou andrógenos, visando o desenvolvimento de caracteres sexuais secundários, apesar do risco de tromboembolismo venoso. Ressalta-se que não foi identificada relação significativa entre TEV e TH em homens transsexuais (CARMO GM, et al., 2020).

O risco de TEV decorre das alterações na cascata de coagulação, pois os estrógenos aumentam a formação de trombina, fatores de coagulação e inibem os fatores anticoagulantes, favorecendo a hipercoagulabilidade e, consequentemente, trombose (CARMO GM, et al., 2020). Já a testosterona atua sobre a endotelina-1, favorecendo à hipertensão por hipertrofia muscular, sem associação com o aumento de eventos vasculares venosos (SEBASTIÃO ML e ACCARDO CM, 2021).

Dessa forma, há maior prevalência de tromboembolismo venoso em transexuais femininos se comparado aos masculinos. Outros fatores são associados como relevantes para o desenvolvimento de fenômenos embólicos como a via de administração, tempo de TH e a formulação usada (CARMO GM, et al., 2020).

\section{CONSIDERAÇÕES FINAIS}

Após a análise dos artigos, foram identificados como fatores preponderantes para a TEV em transgêneros a formulação e o tempo prolongado de uso, além de ser possível observar, maior prevalência dessa enfermidade entre os transexuais que fazem uso de estrógenos em relação ao uso de testosterona.

\section{REFERÊNCIAS}


1. CAMPANA GA, et al. A terapia hormonal no processo de transexualização. Rev Cient FAEMA: Revista da Faculdade de Educação e Meio Ambiente, 2018; 9: 526-531.

2. CARMO GM, et al. Análise do risco de trombose em transexuais devido a terapia hormonal. Brazilian Journal of Development, 2020; 6(9): 71580-71592.

3. SEBASTIÃO ML, ACCARDO CM. Riscos cardiovasculares em transgêneros: revisão da literatura. Revista Eletrônica Acervo Saúde, 2021; 13(1): e5389. 
RESUMO SIMPLES: Revisão Bibliográfica

\section{A INSUFICIÊNCIA PLACENTÁRIA COMO PRINCIPAL CAUSA DE RESTRIÇÃO DE CRESCIMENTO FETAL}

Autor/coautores: Bárbara Quiuqui Soares, Isabela Guedes Paiva, Letícia Luiza Miranda Amaral, Raquel Dias Esteves, Caroline Kíssilla Pereira Pascoal.

Instituição: União Educacional do Vale do Aço (UNIVAÇO), Ipatinga - MG.

Palavras-chave: Retardo do crescimento fetal, RCIU, Gestação.

\section{INTRODUÇÃO}

O acompanhamento do crescimento fetal é um dos objetivos da assistência pré-natal. Quando o desenvolvimento do feto é comprometido, ocorre um aumento do risco de morbimortalidade perinatal, e a longo prazo, pode acarretar danos adversos ao bebê (LESS CC, et al., 2020). A restrição do crescimento intrauterino (RCIU) é um processo capaz de limitar a evolução fetal, e está presente em cerca de 5 a $10 \%$ das gestações (ANTONELLI JDS, et al., 2018). O crescimento fetal depende de vários fatores, no entanto a insuficiência uteroplacentária é uma das causas que mais contribui para este desfecho desfavorável (BENDIX I, et al., 2020).

\section{OBJETIVO}

Analisar a prevalência da disfunção uteroplacentária como principal causa da restrição do crescimento intrauterino e enfatizar a importância da realização de métodos diagnósticos precoces para desfechos mais favoráveis ao crescimento fetal.

\section{REVISÃO BIBLIOGRÁFICA}

As causas da restrição do crescimento intrauterino são diversas, sendo a disfunção uteroplacentária a mais prevalente. A insuficiência placentária (IP) está presente em cerca de $15 \%$ das gestações, sendo que ela é responsável por alterações na circulação fetal, que exigem adaptações hemodinâmicas (FERRAZ MM, et al., 2020). Com isso, o entendimento do processo adaptativo de redistribuição vascular é o principal ponto para uma conduta adequada dessas gestantes (FERRAZ MM, et al., 2020).

As condições materno-fetais incluem o aumento da taxa de condições de prematuridade, alterações no neurodesenvolvimento, maior incidência de doenças como hipertensão arterial sistêmica (HAS), diabetes mellitus tipo 2 (DM2) e síndrome metabólica (LESS CC, et al., 2020). O diagnóstico da RCIU é clínico e ultrassonográfico, sendo a dopplervelocimetria essencial para o estudo dos vasos gestacionais em casos de IP (LESS CC, et al., 2020). Não há tratamento para IP, sendo assim, é imprescindível o monitoramento Doppler fetal, com o objetivo de identificar alterações hemodinâmicas.

\section{CONSIDERAÇÕES FINAIS}

Portanto, são utilizadas diversas abordagens no manejo de uma gestação com RCIU, entretanto, não existe nenhum tratamento efetivo para estimular o crescimento fetal. Desse modo, se faz relevante afirmar a necessidade de realizar o diagnóstico precoce, uma vez que o feto com restrição de crescimento demanda maior acompanhamento em unidades de assistência pré-natal, a fim de que sejam minimizados os riscos de mortalidade e morbidade perinatal. 


\section{REFERÊNCIAS}

1. ANTONELLI JDS, et al. As consequências da restrição de crescimento intrauterino na estrutura e fluxo sanguíneo cerebral: uma revisão da literatura. Femina, 2018; 6: e352-359.

2. BENDIX I, et al. Causes and Consequences of Intrauterine Growth Restriction. Frontiers in endocrinology, 2020;11: e1-3.

3. FERRAZ MM, et al. Aortic Isthmus Doppler Velocimetry in Fetuses with Intrauterine Growth Restriction: A Literature Review. Revista Barsileira de Ginecologia e Obstetrícia, 2020; 42(5): e286-296.

4. LEES CC, et al. ISUOG Practice Guidelines: diagnosis and management of small-for-gestational-age fetus and fetal growth restriction. Ultrasound in obstetrics and gynecology, 2020; 56(2): e:298-312. 
RESUMO SIMPLES: Revisão Bibliográfica

TRANSEXUALIZAÇÃO: REVISÃO DE LITERATURA FOCADA NA PSIQUIATRIA DO PROCESSO

Autores/coautores: Analina Furtado Valadão, Ícaro Silva Magalhães, Letícia Valverde, Matheus Henrique Clemente Corrêa Luz, Matheus Silva Passos.

Instituição União Educacional do Vale do Aço (UNIVAÇO), Ipatinga - MG.

Palavras-chave: Transexualização, Psiquiatria, Saúde mental.

\section{INTRODUÇÃO}

O conceito de transexual se refere àqueles indivíduos que exibem uma discordância entre sexo biológico e gênero, havendo a distinção do sexo psicológico. Historicamente a discriminação e a vulnerabilidade desse grupo vêm conformando uma visão social de estigma e tabu, ainda na contemporaneidade, fato que reflete no sofrimento pessoal, como no âmbito da política e da saúde mental. Mesmo havendo leis com intuito igualitário, é possível perceber que há dificuldades de acesso aos serviços públicos de prevenção e promoção de saúde, evidenciadas pelo despreparo de profissionais e equipes (ALMEIDA CB e VASCONCELLOS VA, 2018).

\section{OBJETIVO}

Analisar a literatura científica acerca do processo transexualização, por meio de uma revisão de literatura com enfoque nos aspectos psiquiátricos evidenciados quanto à abordagem salutar, além dos impasses detectados na corroboração de patologias psíquicas e mentais.

\section{REVISÃO BIBLIOGRÁFICA}

Identidade de gênero constrói-se ao longo do desenvolvimento sexual e biopsicossocial se estabelecendo geralmente na primeira infância podendo ser diferente ao sexo biológico. Ainda, a disforia de gênero, em posição aos caracteres sexuais primários e à identificação sexual, manifesta sinais ansiosos/depressivos que desaparecem, ou não, no início da puberdade e surgimento na adolescência, estendendo para a vida adulta (LERRI MR, et al., 2017).

Não foram encontrados estudos sobre a incidência e prevalência da transexualidade no Brasil, mas em países ocidentais, constata-se 1 em 30.000 homens adultos e 1 em cada 100.000 mulheres adultas procuram cirurgia de redesignação sexual (MONTEIRO SS, et al., 2019).

O processo é composto por tratamentos reversíveis, parcial/total, e irreversíveis com terapêutica acompanhada por equipe multidisciplinar, pela importância da assistência à saúde mental acerca da maior vulnerabilidade desses indivíduos, comparando-se à população geral, pela maior predisposição a ansiedade, depressão e idealização suicida, constatado pela Internacional National Gay and Lesbian Task Force, onde $41 \%$ dos transexuais já tentaram suicídio nos EUA em algum momento, comparado a 1,2\% da população cisgêneros (SOUZA D e IRIART J, 2018).

\section{CONSIDERAÇÕES FINAIS}

Assim, considera-se que os efeitos sobre a saúde mental durante uso da terapia hormonal e de procedimento de reatribuição sexual cirúrgica, demonstram uma melhora nos resultados psicossociais, quanto à disforia de gênero e qualidade de vida. Ademais, ressalta-se a necessidade da estruturação e capacitação da atenção à saúde para tal grupo, mobilizando/reforçando o suporte socioemocional durante esse árduo processo. 


\section{REFERÊNCIAS}

1. ALMEIDA CB, VASCONCELLOS VA. Transexuais: transpondo barreiras no mercado de trabalho em São Paulo. Revista Direito GV, 2018; 14(2): 302-333.

2. LERRI MR, et al. Características clínicas de uma amostra de pessoas transexuais. Revista Brasileira de Ginecologia e Obstetrícia, 2017; 10(39): 545-551.

3. MONTEIRO SS, et al. Saúde e direitos da população trans. Cadernos de Saúde Pública, 2019; 35(4): e00047119.

4. SOUSA D, IRIART J. "Viver dignamente": necessidades e demandas de saúde de homens trans em Salvador, Bahia, Brasil. Cadernos de Saúde Pública, 2018; 34(10): e00036318. 
RESUMO SIMPLES: Revisão Bibliográfica

\section{PERFIL EPIDEMIOLÓGICO DAS UTIS NO BRASIL}

Autor/coautores: Gabriel Calafange Cunha, Joubert Melo Gonçalves, Letícia Guimarães da Fonseca Dias, Márcio Henrique Moreira, Danilo Ribeiro de Miranda.

Instituição: União Educacional do Vale do Aço (UNIVAÇO), Ipatinga - MG.

Palavras-chave: Unidade de Terapia Intensiva, Perfil epidemiológico, Mortalidade.

\section{INTRODUÇÃO}

Nos últimos anos, o desenvolvimento da medicina e do manejo de pacientes graves em Medicina Intensiva vem mudando evolução, tratamento e prognósticos destes. No contexto de Terapia Intensiva, o estudo epidemiológico pode ser usado para coletar informações, permitindo comparações com outras Unidades de Terapia Intensiva (UTI) (FERRÃO A, et al., 2020). As informações desse cunho são essenciais haja vista a importância de compreender as informações clínicas e demográficas de maneira a ajudar e orientar políticas públicas de saúde e direcionar os médicos para um melhor cuidado do paciente crítico (FERRÃO A, et al., 2020).

\section{OBJETIVO}

Abordar o perfil epidemiológico das UTIs no Brasil, sendo esses fatores essenciais para identificar pacientes de maior e menor risco, tornando-se de extrema importância o conhecimento dos médicos acerca do perfil epidemiológico.

\section{REVISÃO BIBLIOGRÁFICA}

Os resultados dos perfis epidemiológicos apontam que, em comparação com o sexo feminino, a proporção de pacientes do sexo masculino nas UTI brasileiras é maior, com faixa etária média de 57,5 anos. Os principais motivos que levaram à internação clínica em UTI foram: doenças cardiovasculares, infecções e sepse, doenças neurológicas e respiratórias. Já nas admissões cirúrgicas, as cirurgias ortopédicas, neurológicas e cardíacas foram as mais prevalentes (AMIB, 2021).

Em relação às comorbidades, a Hipertensão Arterial Sistêmica é a mais comum, seguida por Diabetes Mellitus, Tumores Sólidos, Insuficiência Renal Crônica e Insuficiência Cardíaca (AMIB, 2021). O tempo médio de internação foi de 5,7 dias, com aumento expressivo em pacientes adultos que necessitam de ventilação mecânica (BARCELLOS RA e CHATKIN JM, 2020). Em comparação com o ambiente hospitalar, a taxa de mortalidade na Unidade de Terapia Intensiva é inferior. Idade e pontuação nos escores SAPS 3 e SOFA foram associados com taxa de complicações e mortalidade (JÚNIOR JMS, et al., 2020).

\section{CONSIDERAÇÕES FINAIS}

A partir dessa lógica, observa-se a importância e necessidade de dar a devida atenção aos grupos de alto risco e susceptíveis a internação em UTIs de forma que a equipe médica esteja preparada para recebê-los e atue de maneira que amenize o tempo médio de recuperação desses pacientes.

\section{REFERÊNCIAS}


1. ASSOCIAÇÃO DE MEDICINA INTENSIVA BRASILEIRA (AMIB). Perfil das UTIs. Registro Nacional de Terapia Intensiva, 2021. Disponível em: http://www.utisbrasileiras.com.br. Acessado em 03 de agosto de 2021.

2. BARCELLOS RA, CHATKIN JM. Impact of a multidisciplinary checklist on the duration of invasive mechanical ventilation and length of ICU stay. Jornal Brasileiro de Pneumologia, 2020; 46(3): e20180261.

3. FERRÃO A, et al. Perfil de mortalidade dos pacientes internados em uma Unidade de Terapia Intensiva (UTI) adulto em um hospital universitário do Distrito Federal. Revista Eletrônica Acervo Saúde, 2020; 12(8), e3509.

4. JÚNIOR JMS, et al. Epidemiology and outcome of high-surgical-risk patients admitted to an intensive care unit in Brazil. Revista Brasileira de Terapia Intensiva, 2020; 32(1): 17-27. 
RESUMO SIMPLES: Revisão Bibliográfica

\section{VIOLÊNCIA SEXUAL E COVID-19: UMA PANDEMIA DUPLA?}

Autor/coautores: Camila Moreira Costa, Ana Cláudia Felipe Santiago, Lucas Campos Lopes, Rayane Martins Souza, Caroline Kíssilla Pereira Pascoal.

Instituição: União Educacional do Vale do Aço (UNIVAÇO), Ipatinga - MG.

Palavras-chave: Violência sexual, COVID-19, Pandemia.

\section{INTRODUÇÃO}

Devido à pandemia da COVID-19, medidas de isolamento social foram determinadas na tentativa de impedir a propagação da doença. Consequentemente, houve aumento das ocorrências de violência sexual, principalmente envolvendo mulheres e crianças, perfis historicamente mais atingidos por esse tipo de agravo (MARQUES ES, et al., 2020). A explicação deve-se ao fato de os agressores serem geralmente parte do núcleo interfamiliar. Logo, com a interrupção das aulas presenciais e implantação de trabalhos domiciliares, nota-se uma posição de risco para os grupos supracitados pela ausência do espaço seguro que a escola oferece ou sem o tempo longe da parceria no momento de trabalho (TRAJANO RK, et al., 2021).

\section{OBJETIVO}

Revisar a literatura científica referente a associação entre o aumento do índice de violência sexual e o surgimento da pandemia da COVID-19, bem como estabelecer razões que expliquem tal associação e traçar medidas que visem minimizar a problemática.

\section{REVISÃO BIBLIOGRÁFICA}

Entende-se violência sexual como qualquer ato em que um indivíduo, com uso de força física ou psicológica, tenta obrigar um segundo indivíduo a participar ou ter qualquer tipo de interação sexual (BRASIL, 2021). Vale atentar que, o período de isolamento social trouxe consigo agravos para a saúde mental, colaborando para que a susceptibilidade individual às alterações de comportamento fosse fortemente evidenciada, culminando num processo drástico de mudança das relações sócio-afetivas (GASPAR RS e PEREIRA MUL, 2018).

Desse modo, com o avanço da pandemia da COVID-19, o distanciamento social mostrou-se fator de risco para esse agravo em saúde (ARAGÃO FBA, et al., 2020). As vítimas que já sofriam abuso se tornaram mais suscetíveis a seus algozes e mais pessoas sofreram essa violência por estarem em contato próximo com os agressores (OKABAYASHI NYT, et al., 2020).

Estima-se que os dados acerca da violência sexual durante a pandemia podem ser ainda maiores, uma vez que as escolas, responsáveis por muitas denúncias de violência em outros períodos, ficaram fechadas, corroborando para uma subnotificação desses agravos (TRAJANO RK, et. al., 2021).

\section{CONSIDERAÇÕES FINAIS}

A proximidade vítima-agressor, a dificuldade de acesso aos órgãos responsáveis e a falta de inteligência emocional para lidar com a pandemia são fatores que contribuem para o aumento de abusos sexuais diante do avanço mundial do novo coronavírus. Assim, ampliar ferramentas para realização de denúncias de modo remoto e a educação em saúde, são artifícios importantes para minimizar e vencermos essa pandemia oculta. 


\section{REFERÊNCIAS}

1. ARAGÃO FBA, et al. Perfil de mulheres vítimas de violência sexual no Brasil: antes e depois da pandemia de COVID-19. Research, Society and Development, 2020; 9: e2289108114-e2289108114.

2. BRASIL. Instituto de Pesquisa Econômica Aplicada \& Fórum de Segurança Pública - IPEA.Atlas de violência 2021. Disponível em: https://www.ipea.gov.br/atlasviolencia/. Acessado em: 24 de julho de 2021.

3. GASPAR RS, PEREIRA MUL. Evolução da notificação de violência sexual no Brasil de 2009 a 2013. Cadernos de Saúde Pública [online], 2018; 34: e00172617.

4. MARQUES ES et al. A violência contra mulheres, crianças e adolescentes em tempos de pandemia pela COVID-19: panorama, motivações e formas de enfrentamento. Cadernos de Saúde Pública, 2020; 36: e00074420.

5. OKABAYASHI NYT, et al. Violência contra a mulher e feminicídio no Brasil-impacto do isolamento social pela COVID-19. Brazilian Journal of Health Review, 2020; 3: 4511-4531.

6. TRAJANO RK, et al. Comparativo de casos de violência sexual contra criança e adolescente no período 2018-2020. Research, Society and Development,2021; 10: e11710111384. 
RESUMO SIMPLES: Revisão Bibliográfica

\section{OBESIDADE INFANTIL: QUAIS FATORES TÊM LEVADO O AUMENTO DE PESO ENTRE CRIANÇAS BRASILEIRAS?}

Autor/coautores: Amanda Camillo Camillato, Christiana Assis de Souza, Vitória Valadares Rogério, Catarina Amorim Baccarini Pires.

Instituição: União Educacional do Vale do Aço (UNIVAÇO), Ipatinga - MG.

Palavras-chave: Obesidade, Crianças, Adolescentes.

\section{INTRODUÇÃO}

A obesidade é representada pelo acúmulo excessivo de gordura corporal, acarretando prejuízos à saúde das pessoas (BRASIL, 2019). Trata-se de uma doença de etiologia multifatorial, interagindo fatores, como metabólicos, nutricionais e psicossociais, resultando em balanço energético positivo. A obesidade é a maior epidemia de saúde pública mundial (BORFE L, et al., 2017). No Brasil, há elevada prevalência de sobrepeso e obesidade, afetando crianças e adolescentes. A transição nutricional no país tem acompanhado o processo de mudanças do padrão de nutrição e de consumo, devido às mudanças econômicas, sociais e demográficas no perfil de saúde (BRASIL, 2019).

\section{OBJETIVO}

Compreender a etiologia da obesidade e os fatores envolvidos no aumento da incidência dessa comorbidade entre crianças e adolescentes no Brasil. Além disso, identificar os impactos da obesidade no desenvolvimento desses indivíduos.

\section{REVISÃO BIBLIOGRÁFICA}

Com base na revisão bibliográfica, concluiu-se que a obesidade infantil vem aumentando de forma significativa no Brasil e determina complicações na infância e na vida adulta, já que está associada a doenças como hipertensão, dislipidemia e síndrome metabólica (BORFE L, et al., 2017).

Verificou-se que a obesidade está associada ao perfil socioeconômico, havendo interferência da educação, renda, ocupação e criando padrões de comportamento específicos que afetam diretamente a ingestão calórica, o gasto energético e a taxa de metabolismo. Outro fator a ser considerado é a evolução tecnológica, crianças e adolescentes reduziram o tempo em atividades com maior gasto energético, contribuindo para o aumento da prevalência da obesidade nessa população. Ademais, a obesidade infantil está essencialmente ligada a fatores genéticos e a outros fatores comportamentais, como a ingestão de peptídeos e de proteínas que interferem no metabolismo, levando ao desenvolvimento e a progressão dessa comorbidade (BRASIL, 2019).

Por fim, averiguou-se que a ansiedade é considerada como causa e consequência, ordem e desordem que compõe um quadro composto por vários elementos na compreensão da obesidade infantil (FRONTZEK LGM, et al., 2017).

\section{CONSIDERAÇÕES FINAIS}

Vale salientar a importância de discutir os fatores que têm desencadeado a obesidade infantil, visto que essa representa um risco no desenvolvimento futuro de doenças crônicas, como diabetes mellitus e doenças cardiovasculares, além do comprometimento no estilo de vida da criança e do adolescente, exigindo o desenvolvimento de hábitos saudáveis. 


\section{REFERÊNCIAS}

1. BRASIL. Sociedade Brasileira de Pediatria. Obesidade na infância e adolescência, Manual de Orientação, Departamento Científico de Nutrologia. 2019. Disponível em https://www.sbp.com.br/fileadmin/user_upload/Manual_de_Obesidade_3a_Ed_web_compressed.pdf. Ac essado em: 07 de agosto de 2021.

2. BORFE L, et al. Associação entre a obesidade infantil e a capacidade cardiorrespiratória: revisão sistemática. Revista Brasileira em Promoção da Saúde, 2017; 30(1): e117-124.

3. FRONTZEK LGM, et al. Obesidade infantil: Compreender Para Melhor Intervir. Revista da Abordagem Gestáltica, 2017; 23(2): e167-174. 
RESUMO SIMPLES: Revisão Bibliográfica

\section{ALTERAÇÕES NEUROLÓGICAS NA INFECÇÃO PELO SARS-CoV-2}

Autor/coautores: Bárbara Martins Mello de Oliveira, Henrique Brandião Costa, Kamila Kívia Rosa Batista, Michele Sousa Guimarães, Melissa Araújo Ulhôa Quintão.

Instituição: União Educacional do Vale do Aço (UNIVAÇO), Ipatinga - MG.

Palavras-chave: Covid-19, Manifestações neurológicas, Doenças cerebrovasculares.

\section{INTRODUÇÃO}

Sabe-se que a anosmia é o sintoma neurológico mais comum da Covid-19, porém, outras manifestações estão relacionadas com os efeitos da infecção pelo SARS-CoV-2 no sistema nervoso ou como consequência da resposta imune do organismo contra 0 vírus. Os danos neuronais subdividem-se em três categorias: sintomas musculares esqueléticos, do sistema nervoso periférico e, finalmente, aqueles relacionados ao sistema nervoso central (NORDVIG AS, et al., 2021). O coronavírus apresenta sintomas neurológicos variados, podendo se ressaltar o caso de meningoencefalite viral e autoimune aparente, que é relatada em pacientes acometidos pela patologia em questão (WUA Y, et al., 2020).

\section{OBJETIVO}

Revisar a literatura a respeito da ocorrência de alterações neurológicas em pacientes com infecção ativa pelo SARS-CoV-2 por meio de uma revisão narrativa, com intuito de esclarecer os efeitos do vírus ao sistema nervoso.

\section{REVISÃO BIBLIOGRÁFICA}

Constatou-se que os pacientes costumam apresentar os sintomas neurológicos em média de 3 a 4 dias após o início dos sintomas respiratórios, sendo comuns em indivíduos com histórico de distúrbios neurológicos ou em pacientes previamente saudáveis (ELLUL MA, et al., 2020). No Brasil, estudos contendo relatos de caso de 27 pacientes com sinais, sintomas e complicações neurológicas associadas ao SARS-CoV-2, demonstrou que, dos indivíduos com alguma manifestação neurológica, $48,14 \%$ sofreram um tipo de acidente vascular cerebral, enquanto 25,92\% evoluíram com Síndrome de Guillain-Barré e 14,81\% com encefalite (OLIVEIRA VFL e FERREIRA ENM, 2020).

Em geral, a encefalopatia ocorre por implicação de etiologias tóxico-metabólicas. Entretanto, se medicamentos, hipoxemia ou outras anormalidades laboratoriais não explicarem o comprometimento do paciente, mais avaliações contendo exames complementares devem ser feitas para descartar outras causas, como ressonância magnética, eletroencefalografia e análise do líquido cefalorraquidiano (TSIVGOULIS G, et al., 2020). Além disso, existem relatos na literatura de encefalomielite aguda disseminada e encefalopatia necrosante hemorrágica aguda em paciente com Covid-19 (NEEDHAM EJ, et al., 2020).

\section{CONSIDERAÇÕES FINAIS}

Observa-se que as manifestações mais frequentes nos estudos incluem tontura, cefaléia, mialgias, hipogeusia, hiposmia e, também, distúrbios de menor incidência, como polineuropatia, doenças cerebrovasculares e encefalite. Por isso, é imprescindível que o médico tenha conhecimento em neurologia para tratar as sequelas da Covid-19. 


\section{REFERÊNCIAS}

1. ELLUL MA, et al. Neurological associations of COVID-19. Journal The Lancet Neurology,2020; 19(9):767783.

2. NEEDHAM EJ, et al. Neurological Implications of COVID-19 Infections. Journal Neurocritical Care. 2020; 32:667-671.

3. NORDVIG AS, et al. Potential Neurologic Manifestations of COVID-19. Journal Neurology: Clinical Practice, 2021; 11(2) e135-e146.

4. OLIVEIRA VFL, FERREIRA ENM. Complicações Neurológicas oriundas da infecção por SARS-CoV-2: uma revisão da literatura. Revista Neurociências, 2020; 28:1-14.

5. TSIVGOULIS G, et al. Neurological manifestations and implications of COVID-19 pandemic. Journal Therapeutic Advances in Neurological Disorders, 2020; 13:1-14.

6. WUA Y, et al. Nervous system involvement after infection with COVID-19 and other coronaviruses. Journal Brain, Behavior, and Immunity, 2020; 87:18-22. 
RESUMO SIMPLES: Revisão Bibliográfica

\section{LÚPUS ERITEMATOSO CUTÂNEO: UMA REVISÃO DA LITERATURA}

Autor/coautores: Ana Luiza Faria Rabelo, Lorena Rodrigues Dias Martins Silva, Lurianny Dias Ferreira, Pedro Duarte Moreira Andrade, Ismael Alves Rodrigues Junior.

Instituição: União Educacional do Vale do Aço (UNIVAÇO), Ipatinga - MG.

Palavras-chave: Lúpus Eritematoso Cutâneo, Manifestações cutâneas de lúpus, Lúpus Eritematoso Sistêmico.

\section{INTRODUÇÃO}

O Lúpus Eritematoso Sistêmico (LES) é uma doença autoimune complexa, desencadeada por inúmeros fatores como interação genética, fatores ambientais, hormonais e até mesmo pela etnia do paciente. $O$ envolvimento da parte cutânea é muito comum de ser observado em pacientes com LES, o que gera um impacto significativo na qualidade de vida e no prognóstico dos pacientes (BLAKE SC e DANIEL BS, 2019). As mulheres apresentam maior incidência de Lúpus Eritematoso Cutâneo (LEC) e de LES em todas as faixas etárias e etnias, sendo o pico de incidência observado no meio da vida adulta (REES F, et al., 2017).

\section{OBJETIVO}

Revisar brevemente a literatura científica sobre a frequência de ocorrência do Lúpus Eritematoso Cutâneo, investigar quais são os grupos de risco e como é o tratamento e o prognóstico dos pacientes acometidos por essa patologia.

\section{REVISÃO BIBLIOGRÁFICA}

O LEC ocorre em $75 \%$ a $80 \%$ dos pacientes que possuem LES e pode ser classificado como manifestações cutâneas específicas ou inespecíficas (KUHN A, et al., 2017). O lúpus cutâneo específico pode ser classificado em LE cutâneo agudo (LECA), LE cutâneo e LE cutâneo crônico (LECC). Os achados histológicos são semelhantes em todas as formas e a diferenciação entre os subtipos não é possível apenas com a histologia, sendo necessário exames mais detalhados (PETTY AJ, et al., 2020).

Além da genética e do sexo feminino, os fatores ambientais e o tabagismo estão diretamente relacionados ao aumento da atividade da doença e à pior resposta aos tratamentos convencionais (STOHL W, et al., 2017). Além disso, há uma forte associação entre LEC e a radiação ultravioleta (UV) (PETTY AJ, et al., 2020).

O diagnóstico de LEC é feito por meio dos sintomas clínicos em combinação com testes sorológicos, histopatológicos e teste de autoanticorpos. Fotoproteção, corticosteróides tópicos em curto prazo e antimaláricos como a Hidroxicloroquina, mostraram-se efetivos no tratamento e prognóstico de pacientes com LEC (CHASSET F, et al., 2017).

\section{CONSIDERAÇÕES FINAIS}

O LEC é uma doença autoimune complexa e possui diversos subtipos que devem ser considerados e tratados individualmente para melhor prognóstico do paciente. A fotoproteção e os corticosteróides tópicos, aliados aos antimaláricos continuam sendo o padrão ouro para os pacientes com doença cutânea. No entanto, mais pesquisas são necessárias para uma melhor compreensão de sua patologia e para uma melhor definição do LEC dentro do contexto da LES. 


\section{REFERÊNCIAS}

1. BLAKE SC, DANIEL BS. Lúpus eritematoso cutâneo: uma revisão da literatura. Int J Womens Dermatol, 2019; 5 (5): 320-329.

2. CHASSET $F$, et al. Eficácia e comparação de antimaláricos em subtipos de lúpus eritematoso cutâneo: Uma revisão sistemática e meta-análise. Br J Dermatology, 2017; 1771 (1): 188-196.

3. KUHN A, et al. Diretriz para o tratamento do lúpus eritematoso cutâneo - guiada pelo European Dermatology Forum (EDF) em cooperação com a European Academy of Dermatology and Venerology (JEADV). J Eur Acad Dermatol Venerol, 2017; 31: 389-404.

4. PETTY AJ, et al. Lúpus eritematoso cutâneo: progresso e desafios. Curr Allergy Asthma Rep, 2020; 20 (5): 12.

5. REES F, et al. A incidência mundial e prevalência de lúpus eritematoso sistêmico: Uma revisão sistemática de estudos epidemiológicos. J Eur Acad Dermatol Venerol, 2017; 56 (11): 1945-1961.

6. STOHL, W, et al. Efficacy and safety of subcutaneous belimumab in systemic lupus erythematosus: A randomized, double-blind, placebo-controlled, 52-week study. Arthritis Rheumatol, 2017. 
RESUMO SIMPLES: Revisão Bibliográfica

\section{COMPLICAÇÕES CARDIOVASCULARES DA COVID 19}

Autor/coautores: Jamile Cássia Gonçalves Aniceto Ferreira, Jyennyffer Barral Rodrigues, Letícia Andrade de Souza, Lucas Lara Oliveira, Raphael Diniz e Silva

Instituição: União Educacional do Vale do Aço (UNIVAÇO), Ipatinga - MG.

Palavras-chaves: COVID-19, Complicações cardiovasculares, Coronavírus.

\section{INTRODUÇÃO}

Pacientes contaminados com a COVID-19 possuem uma incidência elevada de sintomas cardiovasculares, devido a resposta inflamatória sistêmica e dos distúrbios imunológicos que ocorrem durante o progresso da doença (FERRARI F, 2020). A Injúria cardiovascular ocorre por uma desproporção entre o aumento da demanda metabólica/ inflamatória provocada pelo vírus e uma redução da reserva cardíaca, o que torna o ambiente mais propenso para eventos trombóticos (COSTA JA, et al., 2020). O dano cardíaco acontece, principalmente, em pacientes com idade avançada, hipertensão, diabetes, doença coronária prévia e pode desencadear diversas manifestações como: injúria miocárdica, insuficiência cardíaca, síndrome de Takotsubo (ST), arritmias, miocardite e choque (COSTA IBSS, et al., 2020).

\section{OBJETIVO}

Realizar uma revisão de literatura sobre as complicações cardiovasculares da COVID-19 e os possíveis danos da doença para o sistema cardíaco com base em artigos e documentos retirados do banco de dados da área da saúde.

\section{REVISÃO BIBLIOGRÁFICA}

Sabe-se que o vírus da COVID-19 ataca o sistema cardiovascular e afeta o paciente de diversas maneiras como manifestações de dano miocárdico, insuficiência cardíaca, ST, arritmias, miocardite e choque. Esse dano cardiovascular ocorre principalmente em pacientes com fatores de risco cardiovascular, como, idosos, hipertensos e diabéticos ou com doença cardíaca prévia (COSTA IBSS, et al., 2020).

A lesão do miocárdio relacionada com SARS-CoV-2 foi descrita em 5 pacientes dos primeiros 41 diagnosticados com a doença em Wuhan, que apresentaram troponina cardíaca I de alta sensibilidade $>28$ $\mathrm{pg} / \mathrm{ml}$. (FERRARI F, 2020). Um relato de caso mostrou que 16,7\% dos pacientes, em 138, hospitalizados por COVID-19 apresentaram arritmia e 7,2\% sofreram lesão cardíaca aguda (COSTA JA, et al., 2020).

Com isso, sabe-se que a incidência de manifestações cardiovasculares é relevante, por conta da resposta inflamatória sistêmica e distúrbios imunológicos na progressão da doença. Nesse sentido, pacientes com doenças cardiovasculares prévias podem apresentar pior prognóstico, devendo ter atenção especial no tratamento da SARS-CoV-2 (FERRARI F, 2020).

\section{CONSIDERAÇÕES FINAIS}

Mediante as complicações cardiovasculares que o vírus do COVID-19 proporciona aos indivíduos que se infectaram, faz-se necessário enfatizar à população sobre a gravidade da doença e sinalizar principalmente aos mais vulneráveis sobre o risco de desenvolver um dano maior após a infecção, incentivando a vacinação e ao isolamento social para achatamento da curva de contaminação. 


\section{REFERÊNCIAS}

1. COSTA IBSS, et al. O coração e a COVID-19: o que o cardiologista precisa saber?.Arquivo Brasileiro de Cardiologia,2020;114(5):805-816.

2. COSTA JA, et al. Implicações cardiovasculares em pacientes infectados com COVID-19 e a importância do isolamento social para reduzir a disseminação da doença. Arquivo Brasileiro de Cardiologia, 2020; 114(5):834-838.

3. FERRARI F. COVID-19: dados atualizados e sua relação com o sistema cardiovascular. Arquivo Brasileiro de Cardiologia, 2020; 114(5):823-826. 
RESUMO SIMPLES: Revisão Bibliográfica

\section{QUEDAS EM IDOSOS E O PAPEL DA ATENÇÃO PRIMÁRIA À SAÚDE}

Autor/coautores: Gabriel Gonçalves Souza, João Gabriel Leite, Juliana Silva Vidal Pereira, Ana Laura Barros Lana, Sávio Francisco Ulhôa.

Instituição: União Educacional do Vale do Aço (UNIVAÇO), Ipatinga - MG.

Palavras-chave: Queda, Idosos, APS.

\section{INTRODUÇÃO}

A incidência anual de quedas em idosos é um problema de saúde pública e de grande impacto social (WINGERTER DG, et al., 2020). O envelhecimento está associado à redução da massa muscular e óssea, além da perda de equilíbrio postural. Assim, vale ressaltar que a queda é o principal mecanismo de trauma em idosos e leva a um prognóstico ruim, sendo necessário enfoque sobre medidas preventivas e abordagem múltipla/integral às causas desse acontecimento. Por fim, dentre as intervenções supracitadas para garantir a segurança dessa parcela da sociedade, encontram-se: otimização medicamentosa, controle ambiental, atividade física e correção visual (SOUZA LHR, et al., 2017).

\section{OBJETIVO}

Revisar a literatura científica acerca das quedas em idosos, suas causas e o papel dos profissionais da Atenção Primária à Saúde (APS) na elaboração de estratégias para prevenção e manejo de eventos dessa natureza.

\section{REVISÃO BIBLIOGRÁFICA}

As quedas estão entre os principais fatores que ameaçam a independência e a vida dos idosos, sendo causadas e agravadas por fatores extrínsecos/intrínsecos que comprometem o envelhecimento ativo, levando à perda da independência, autonomia e, algumas vezes, óbito (CARLIF VBO, et al., 2019).

A abordagem do médico de família e comunidade, juntamente à equipe multidisciplinar, é essencial na identificação e elaboração de estratégias, especialmente nos cuidados preventivos, uma vez que podem passar sem atenção clínica no momento do atendimento. A abordagem adequada na Atenção Primária à Saúde, como triagem de pacientes vulneráveis, avaliação de fatores de risco, identificação da causa em quedas prévias e a recomendação de intervenções para reduzir esse risco, são essenciais. Ferramentas de geoinformação podem auxiliar no direcionamento das estratégias de atuação e fortalecimento do acesso a serviços de saúde, proporcionando melhores condições de vida e longevidade ao idoso (MORELAND B, et al., 2020; FREITAS FFQ, et al., 2020).

\section{CONSIDERAÇÕES FINAIS}

A queda em idosos é um problema de saúde resultante de frequentes acidentes domésticos. Destaca-se o papel do profissional de saúde na promoção de práticas e estratégias redutoras desta problemática, desde a implementação de atividades físicas, que potencializam a força muscular, até a otimização da medicação. Assim observa-se a diminuição da morbimortalidade e dos custos hospitalares.

\section{REFERÊNCIAS}


1. CARLIF VBO, et al. Ocorrências de quedas em idosos e a polifarmácia. Revista Eletrônica Acervo Saúde, 2019; 37: e1082.

2. FREITAS FFQ, et al. Fragilidade em idosos na Atenção Primária à Saúde: uma abordagem a partir do geoprocessamento. Ciência \& Saúde Coletiva, 2020; 25:4439-4450.

3. MORELAND B, et al. Trends in Nonfatal Falls and Fall-Related Injuries Among Adults Aged $\geq 65$ Years United States, 2012-2018. Morbidity and Mortality Weekly Report, 2020; 69:875.

4. SOUZA LHR, et al. Queda em idosos e fatores de risco associados. Rev. Aten. Saúde. 2017;15(54):5560.

5. WINGERTER DG, et al. Mortalidade por queda em idosos: uma revisão integrativa. Revista Ciência Plural. 2020; 6:119-136. 
RESUMO SIMPLES: Revisão Bibliográfica

PROPOSTA DE IMPLANTAÇÃO DE JOGOS PARA O APRENDIZADO DO INGLÊS MÉDICO: SERIA ESSA UMA SOLUÇÃO PARA APROXIMAR O ESTUDANTE DA LÍNGUA INGLESA?

Autor/coautores: Catarina Amorim Baccarini Pires, Clara Elise Teixeira de Paiva, Emilly Eleutério Silva, Marcelly Silva Moreira.

Instituição: União Educacional do Vale do Aço (UNIVAÇO), Ipatinga - MG.

Palavras-chave: Inglês médico, Gamificação, Aprendizagem.

\section{INTRODUÇÃO}

O ensino por metodologias ativas vem adquirindo cada vez mais espaço no cenário da educação médica e a aplicação dos jogos, um método ativo, nos problemas da realidade, demonstra capacidade de integrar o estudante ao processo de aprendizagem (GENTRY SV, et al., 2019; PAIVA JHHGL, et al., 2019.). Ademais, a compreensão do inglês se mostra necessária na medicina tendo em vista que o médico destaca-se no mercado de trabalho quando se atualiza por fontes em inglês e ainda mais quando participa de experiências acadêmicas no exterior (POSEGGER KR, 2019). Portanto, o aprendizado ativo aliado ao ensino do inglês médico possibilitará uma melhor experiência acadêmica para os alunos.

\section{OBJETIVO}

Revisar a literatura científica para compreender se a gamificação, como ferramenta de promoção do ensino, sobretudo do inglês médico, é estratégia eficaz no estímulo à aprendizagem, bem como possibilita a integração dos alunos ativamente.

\section{REVISÃO BIBLIOGRÁFICA}

Para atender às necessidades da geração atual, imersa na internet, o uso de jogos para o ensino tem se mostrado um promotor do aprendizado, aumentando o engajamento e preparando o aluno para situações do mundo (MCCOY L, et al., 2016). Os resultados são promissores quanto ao uso da gamificação voltada para a educação médica por melhorar as habilidades e a satisfação do estudante e, quando alinhada com os objetivos de aprendizagem, possuírem o potencial de motivar o aluno na obtenção do conhecimento (GENTRY SV, et al., 2019; RUTLEDGE C, et al., 2018).

Além disso, em estudos realizados com estudantes de medicina para se comprovar a eficácia da gamificação como estratégia de aprendizagem, observou-se que o método facilitou o aprendizado quando comparada a atividades do ensino tradicional, bem como despertou o interesse em continuar estudando os assuntos abordados (PAIVA JHHGL, et al., 2019).

\section{CONSIDERAÇÕES FINAIS}

O uso de estratégias de gamificação vem se tornando campo de crescimento acelerado e demonstrando potencial de desenvolver o aprendizado do inglês médico. Assim, propõe-se a elaboração de um jogo de perguntas sobre o inglês médico, através da plataforma KAHOOT, que serão liberados periodicamente para o acompanhamento dos acadêmicos, incentivando o desenvolvimento linguístico e contribuindo para fixar 0 vocabulário.

\section{REFERÊNCIAS}


1. GENTRY SV, et al. Serious Gaming and Gamification Education in Health Professions: Systematic Review. Journal of medical Internet research, 2019; 21(3): e12994.

2. MCCOY L, et al. Gamification and Multimedia for Medical Education: A Landscape Review. Journal of the American Osteopathic Association, 2016; 116 (1): 22-34.

3. PAIVA, JHHGL, et al. O Uso da Estratégia de Gamificação na Educação Médica. Revista Brasileira de Educação Médica, 2019; 43 (1): 147-156.

4. POSEGGER, KR. A Importância do Inglês na Medicina e no Desenvolvimento Profissional. Revista Ciências em Saúde, 2019; 9(3): 1-2.

6. RUTLEDGE C, et al. Gamification in Action: Theoretical and Practical Considerations for Medical Educators. Academic Medicine, 2018; 93 (7): 1014-1020. 
RESUMO SIMPLES: Revisão Bibliográfica

\section{ABORDAGEM DA DISQUESIA DO LACTENTE: REVISÃO DE LITERATURA}

Autor/coautores: Ana Carolina Lima Barros, Alice Marina de Almeida Condé, Kellen Letícia Sarmento, Catarina Amorim Baccarini Pires.

Instituição: União Educacional do Vale do Aço (UNIVAÇO), Ipatinga - MG.

Palavras-chave: Lactente, Gastroenteropatias, Pediatria.

\section{INTRODUÇÃO}

Os cuidados com o recém-nascido são desafiadores para os pais. Enquanto o intestino está amadurecendo, crianças com aleitamento materno exclusivo podem evacuar fezes líquidas várias vezes ao dia ou permanecer alguns dias sem defecar e isso não é considerado constipação (BASTOS MD, et al., 2017). Os quadros com pelo menos 10 minutos de esforço e choro antes da eliminação bem-sucedida ou não das fezes moles em crianças de até nove meses e sem outros problemas de saúde recebem o diagnóstico de disquesia do lactente (ZEEVENHOOVEN J, et al., 2017). As manifestações do esforço na ausência de constipação são rubor ou coloração arroxeada no rosto, gemidos, suor e choro.

\section{OBJETIVO}

Revisar a literatura científica sobre a disquesia do lactente, reconhecer os critérios diagnósticos dessa desordem do funcionamento gastrointestinal descrita como defecação ineficaz e conhecer as práticas que devem ser realizadas e as que devem ser evitadas no manejo adequado.

\section{REVISÃO BIBLIOGRÁFICA}

Conforme o critério Roma IV, a disquesia infantil é um distúrbio funcional causado por falha em coordenar - aumento da pressão intra-abdominal com o relaxamento dos músculos do assoalho pélvico (ZEEVENHOOVEN J, et al., 2017). No exame clínico, é fundamental questionar sobre a dieta, excluir anormalidades anorretais e avaliar a curva de crescimento do bebê. A disquesia atinge cerca de $15 \%$ dos lactentes, é apenas menos prevalente do que a cólica, e geralmente resolve-se espontaneamente após 3-4 semanas ou até os nove meses (CHOGLE A, et al., 2018).

Os pais podem auxiliar consolando o bebê, com massagens suaves e dobrando as pernas do lactente sobre a barriga dele. A estimulação retal pode ser contraproducente e laxantes são desnecessários (BENNINGA MA, et al., 2016). Bebês com disquesia devem ser diferenciados daqueles com evacuações dolorosas devido às fissuras anais ou proctite induzida por proteína alimentar. Os bebês que sentem dor ao defecar podem aprender um comportamento de contenção (HO JMD e HOW CH, 2020). Isso se manifesta pelo enrijecimento do corpo e pelo rubor do rosto, assemelhando-se à disquesia.

\section{CONSIDERAÇÕES FINAIS}

Portanto, é importante avaliar um lactente com suspeita de disquesia para determinar se os movimentos intestinais são difíceis ou se há qualquer evidência de fissura anal ou irritação e realizar o diagnóstico diferencial de outras condições gastrointestinais. Apesar de ser desafiador o diagnóstico por depender do relato e da interpretação dos pais sobre os sintomas dos filhos, o clínico deve saber orientar e acalmar os cuidadores. 


\section{REFERÊNCIAS}

1. BASTOS MD. Características da Constipação Funcional em Crianças de Zero a Doze Anos Atendidas em um Ambulatório de Gastroenterologia Pediátrica. Revista de Epidemiologia e Controle de Infecção, 2018; 8(4): 415-421.

2. BENNINGA MA, et al. Childhood Functional Gastrointestinal Disorders: Neonate/Toddler. Gastroenterology, 2016; 150(6): 1443-1455.

3. CHOGLE A, et al. Multicountry cross-sectional study found that functional gastrointestinal disorders such as colic and functional dyschezia were common in South American infants. Acta Paediatric, 2018; 107: 708-713.

4. $\mathrm{HO}$ JMD, HOW $\mathrm{CH}$. Chronic constipation in infants and children. Singapore Medicine Journal. 2020;61(2):63-68.

5. ZEEVENHOOVEN J, et al. The New Rome IV Criteria for Functional Gastrointestinal Disorders in Infants and Toddlers. Pediatric Gastroenteroly, Hepatology Nutrition, 2017; 20(1):1-13. 
RESUMO SIMPLES: Revisão Bibliográfica

\section{SONO E IMUNIDADE: UMA REVISÃO DE LITERATURA}

Autor/coautores: Ana Carolina Vale Campos Lisbôa, Ana Luiza Andrade Fantoni, Luan José Martins Pereira, Sabrina Maria Diniz Morais Lage.

Instituição: União Educacional do Vale do Aço (UNIVAÇO), Ipatinga - MG.

Palavras-chave: Sono, Sistema imune, Imunidade.

\section{INTRODUÇÃO}

O sono é imprescindível para o ser humano, pois além de ocupar um terço da sua vida, mantém a homeostase corporal (RICO-ROSILLO MG e VEGA-ROBLEDO GB, 2018). Entretanto, com a modificação do ritmo circadiano, atrelada aos problemas psicológicos e mudança dos hábitos de vida, observa-se, tualmente, um comprometimento da qualidade do sono e consequentemente do funcionamento do sistema imune (SILVA ESM, et al., 2020). Assim, é importante conhecer quais processos imunológicos são mais sensíveis à privação do sono e as consequências para o organismo diante do comprometimento do desempenho desse importante regulador do organismo (RICO-ROSILLO MG e VEGA-ROBLEDO GB, 2018).

\section{OBJETIVO}

Conhecer os principais efeitos da privação do sono sobre o sistema imune por meio de uma revisão da literatura científica, dos últimos cinco anos, sabendo-se da importância desse assunto para a comunidade.

\section{REVISÃO BIBLIOGRÁFICA}

Após aplicar os critérios de inclusão e exclusão foram selecionados 8 artigos, finalizando com os três das revistas de maior impacto. O sono se mostrou essencial para que o indivíduo seja capaz de manter a regulação da resposta imune, e com ele ocorre a restauração da energia, eliminação de radicais livres, ajuste endócrino e da atividade elétrica cortical e solidificação da memória. (SILVA ESM, et al., 2020). Ele pode modificar a função do sistema imunológico por induzir alterações no eixo hipotálamo-pituitária-adrenal e no sistema nervoso simpático (RICO-ROSILLO MG e VEGA-ROBLEDO GB, 2018).

Estudos mostraram que a sua privação produz alterações fisiológicas, induzindo um aumento na imunidade inata que envolve citocinas como interleucina-6 (IL-6) e o fator de necrose tumoral-alfa (TNF- $\alpha$ ), diminuição da adaptativa, maior risco de infecções graves e, até mesmo, ao envelhecimento celular (IRWIN MR e OPP MR, 2017).

\section{CONSIDERAÇÕES FINAIS}

Diante do exposto, considera-se que o sono tem importância significativa para o estabelecimento de uma imunidade adequada. Outrossim, as mudanças que têm sido vistas nos hábitos de sono na sociedade moderna, contribuem para que os mecanismos imunes estejam alterados. Portanto, há prejuízos no funcionamento adequado do sistema imunológico.

\section{REFERÊNCIAS}

1. IRWIN MR, OPP MR. Sleep Health: Reciprocal Regulation of Sleep and Innate Immunity. Nat Rev Immunol, 2019; 19(11): 702-715. 
2. RICO-ROSILLO MG, VEGA-ROBLEDO GB. Sueño y sistema immune. Revista Alergia Mexico, 2018; 65(2): 160-170.

3. SILVA ESM, et al. Sleep and immunity in times of COVID-19. Revista da Associação Médica Brasileira, 2020; 66(2): 143-147. 
RESUMO SIMPLES: Revisão Bibliográfica

\section{DEPRESSÃO PÓS-PARTO E SUAS CONSEQUÊNCIAS}

Autor/coautores: Lucas Duarte Magalhães, Ana Laura Miranda Campanha, Júlia Sá Nascimento, Sara Almeida Moreira, Caroline Kíssilla Pereira Pascoal.

Instituição: União Educacional do Vale do Aço (UNIVAÇO), Ipatinga - MG.

Palavras-chave: Depressão pós-parto, Transtorno depressivo, Obstetrícia.

\section{INTRODUÇÃO}

A depressão puerperal é uma desordem psiquiátrica que cursa com humor deprimido, perda de interesse, alterações no sono, alterações no apetite, perda de energia, sentimento de culpa, irritabilidade, ansiedade, diminuição da concentração e pensamentos suicidas, com início durante a gravidez ou dentro de 4 semanas após o parto (STEWART DE e VIGOD S, 2016). É a complicação mais comum do parto e prejudica drasticamente a qualidade de vida materna, podendo interferir na amamentação, no vínculo mãe-bebê, no cuidado com a criança e na relação com o parceiro. Nesse sentido, o suicídio é responsável por aproximadamente $20 \%$ das mortes pós-parto (PAYNE JL e MAGUIRE J, 2019).

\section{OBJETIVO}

Revisar a literatura científica acerca da depressão pós-parto, visando compreender as principais consequências, para a mãe e para o bebê, e os impactos na qualidade de vida das mulheres acometidas com essa patologia.

\section{REVISÃO BIBLIOGRÁFICA}

No período pós-parto, a maioria das mulheres ocorre o baby blues (tristeza puerperal), que é caracterizado por um distúrbio de humor leve e transitório. Inicia-se normalmente entre o terceiro e o quinto dia após o parto, mas é autolimitado. Entretanto, este quadro, assim como história de depressão, depressão e ansiedade durante a gravidez, neuroticismo, baixa autoestima, eventos de vida estressantes, insatisfação conjugal e baixo suporte social são considerados fatores de risco para o desenvolvimento de depressão pós-parto (DPP) (SLOMIAN J, et al., 2019).

Nesse sentido, foram observadas as consequências que a DPP pode causar na vida dessas mães, notando-se o surgimento de outros transtornos parte delas, como o Transtorno de Ansiedade Generalizada e o Transtorno Depressivo Maior. Além disso, observou-se mudanças na qualidade de vida materna, como menor atenção e dedicação no cuidado do bebê, o que pode provocar maior dificuldade de vínculo e insegurança materna. Assim, essa relação comprometida entre mãe-bebê pode contribuir para o comprometimento do desenvolvimento neurobiológico, social e cognitivo da criança (SLOMIAN J, et al., 2019; STEWART DE e VIGOD S, 2016).

\section{CONSIDERAÇÕES FINAIS}

A depressão pós-parto é uma conjuntura de profunda tristeza, que acomete grande partes das mulheres no puerpério e a falta de informação contribui para a intensificação dos sintomas, por conseguinte, a saúde mental da mãe fica ainda mais vulnerável, afetando o vínculo afetivo com o bebê. Com isso, inúmeras consequências negativas são descritas na literatura sobre a vida do recém-nascido, além de sequelas prolongadas na infância e adolescência. 


\section{REFERÊNCIAS}

1. PAYNE JL, MAGUIRE J. Pathophysiological mechanisms implicated in postpartum depression. Frontiers in Neuroendocrinology, 2019; 52: 165-180.

2. SLOMIAN J, et al. Consequences of maternal postpartum depression: A systematic review of maternal and infant outcomes.Women's Health, 2019; 15: 1-55.

3. STEWART DE, VIGOD S. Postpartum depression. New England Journal of Medicine, 2016; 375(22): 21772186. 
RESUMO SIMPLES: Revisão Bibliográfica

\section{SÍNDROME DE BLAU: REVISÃO DE LITERATURA}

Autor/coautores: Layandra Vittória de Assis, Maria Laura Klein Lazaroto, Príncia Christino de Abreu Carvalho, Renata Silva Ferreira, Ismael Alves Rodrigues Junior.

Instituição: União Educacional do Vale do Aço (UNIVAÇO), Ipatinga - MG

Palavras-chave: Síndrome de Blau, Gene NORD2, Doença autoinflamatória.

\section{INTRODUÇÃO}

A síndrome de Blau (SB) é uma patologia autoinflamatória autossômica dominante, decorrente de mutações no gene que sistematiza a ligação de nucleotídeo na proteína 2 (NORD 2), que é definida por artrite, erupção cutânea e uveíte (OTSUBO Y, et al., 2017). Em relação a SB, há diversos estudos sobre a fisiopatologia que demonstram que os sintomas iniciam antes dos 4 anos de idade, de forma progressiva com desenvolvimento de complicações graves, no entanto no cenário atual não há tratamento que apresentou eficácia no controle e na cura da doença (SANAMI T, et al., 2018).

\section{OBJETIVO}

Revisar a literatura científica sobre a SB, elucidando etiologia, epidemiologia, fisiopatologia, manifestações clínicas, complicações, diagnóstico, sinais, sintomas e o manejo adequado dessa doença de caráter auto inflamatório e hereditário.

\section{REVISÃO BIBLIOGRÁFICA}

A tríade clássica da SB é: artrite, dermatite e uveíte. Os sintomas iniciais incluem placas eritematosas escamosas com múltiplas pápulas liquenóides. A artrite é a manifestação mais comum e apresenta-se de forma simétrica, indolor e tenossinovite, com edema das articulações, podendo evoluir com limitação do movimento e camptodactilia. A uveíte está associada à alta morbidade e os pacientes podem desenvolver panuveíte granulomatosa (MATSUDA T, et al., 2020).

O diagnóstico é clínico a partir da tríade clássica. Além disso, biópsia de pele ou sinóvia pode identificar granulomas e o teste genético pode mostrar mutações no gene NOD2. O tratamento com o uso de antiinflamatórios não esteroides, corticosteroides e metotrexato, tem sido relatado até o momento. No entanto, agentes biológicos podem ser uma abordagem promissora para pacientes que não respondem ao tratamento tradicional (SANTANA JCD, et al., 2019; CHEN J, et al., 2019).

\section{CONSIDERAÇÕES FINAIS}

Portanto, a avaliação de um paciente suspeito de SB é de suma importância, visto que se elucidado o diagnóstico precocemente, é possível que haja maior controle da doença. Ainda, cabe ressaltar a necessidade de se oferecer um tratamento multidisciplinar capaz de conter as diferentes manifestações da patologia e melhorar a vida do paciente.

\section{REFERÊNCIAS}

1. CHEN J, et al. Effective treatment of TNFa inhibitors in Chinese patients with Blau syndrome. Arthritis Research \& Therapy, 2019; 21: 236. 
2. MATSUDA T, et al. Clinical characteristics and treatment of 50 cases of Blau syndrome in Japan confirmed by genetic analysis of the NOD2 mutation. Annals of the Rheumatic Diseases, 2020; 0:1-8.

3. OTSUBO Y, et al. A long-term follow-up of Japanese mother and her daughter with Blau syndrome: Effective treatment of anti-TNF inhibitors and useful diagnostic tool of joint ultrasound examination. Modern Rheumatology, 2017; 27: 169-173.

4. SANAMI T, et al. Pluripotent stem cell models of Blau syndrome reveal an IFN-y-dependent inflammatory response in macrophages. J Allergy Clin Immunol, 2018; 141: 339-439.

5. SANTANA JCD, et al. Síndrome de Blau: infiltrados subepiteliais como manifestações oftalmológicas incomuns. Revista Brasileira de Oftalmologia, 2019; 78 (1): 62-4.4 
RESUMO SIMPLES: Revisão Bibliográfica

\section{O PAPEL DA ATIVIDADE FÍSICA NO TRATAMENTO DE TRANSTORNOS DE ANSIEDADE}

Autor/coautores: Aline Ferreira de Souza, Gabriela Mozdzen dos Passos, lara Giovana Souza Silva, Rayenne Rodrigues Nascente, Maurício Lacerda Caldeira Filho.

Instituição: União Educacional do Vale do Aço (UNIVAÇO), Ipatinga - MG.

Palavras-chave: Atividade física, Ansiedade, Psiquiatria.

\section{INTRODUÇÃO}

A ansiedade é característica inerente ao ser humano. Trata-se de uma resposta adaptativa a ameaças, mas pode evoluir de forma disfuncional, conforme o subtipo (STUBBS B, et al., 2017a). Os Transtornos de Ansiedade (TA) são prevalentes, geram impacto direto no bem-estar dos indivíduos, além de aumentar o risco de doenças cardiovasculares (KANDOLA A, et al., 2018). Sendo assim, é fundamental o tratamento adequado e multidisciplinar (STUBBS B, et al., 2017b). Nesse sentido, estudos apontam que a prática de atividade física pode levar à redução dos sintomas dos TA além de gerar impacto positivo na qualidade de vida dos indivíduos (MCDOWELL CP, et al., 2019).

\section{OBJETIVO}

Revisar a literatura científica acerca da prevalência dos TA, comorbidades que podem estar associadas e os benefícios da prática de exercícios, a fim de eleger a atividade física como forma de tratamento e prevenção desses transtornos.

\section{REVISÃO BIBLIOGRÁFICA}

Dentre as patologias mentais, os TA englobam diferentes diagnósticos, sendo eles: transtorno de ansiedade generalizada (TAG), transtorno do pânico (TP), fobia social, e fobias específicas (STUBBS B, et al., 2017a). Possuem prevalência global de 3,8\% a 25\%, chegando a 70\% em indivíduos diagnosticados com doenças crônicas (KANDOLA A, et al., 2018). Frequentemente estão associados à comorbidades e cursam com aumento da morbidade, mortalidade prematura e doenças cardiovasculares (STUBBS B, et al., 2017b).

Devido ao alto predomínio dos TA, tratamento de alto custo, baixa adesão à terapêutica e ao elevado índice de tratamentos inadequados, é notória a necessidade de estratégias não farmacológicas e de baixo custo para a prevenção e manejo desses transtornos (MCDOWELL CP, et al., 2019). Nesse contexto, revisões sistemáticas e meta-análises, estudos de alta relevância, evidenciaram redução dos sintomas de ansiedade mediante o esforço físico da musculatura esquelética (MCDOWELL CP, et al., 2019). Dessa forma, elegem a prática de atividade física como estratégia terapêutica e preventiva eficaz (MCDOWELL CP, et al., 2019).

\section{CONSIDERAÇÕES FINAIS}

As evidências presentes na literatura científica apontam os benefícios da atividade física no controle dos sintomas dos Transtornos de Ansiedade. Sendo assim, é desejável que os serviços de atendimento psiquiátrico ofereçam, adjunta às terapias estabelecidas, orientações sobre a prática de exercícios, de modo que promova melhores resultados terapêuticos, além de fornecer bem-estar ao indivíduo durante seu tratamento. 


\section{REFERÊNCIAS}

1. KANDOLA A, et al. Moving to Beat Anxiety: Epidemiology and Therapeutic Issues with Physical Activity for Anxiety. Current Psychiatry Reports, 2018; 20: 1-9.

2. MCDOWELL CP, et al. Physical Activity and Anxiety: A Systematic Review and Meta-analysis of Prospective Cohort Studies. American Journal of Preventive Medicine, 2019; 57: 545-556.

3. STUBBS B, et al. An examination of the anxiolytic effects of exercise for people with anxiety and stressrelated disorders: A meta-analysis. Psychiatry Research, 2017a; 249: 102-108.

4. STUBBS B, et al. Physical activity and anxiety: A perspective from the World Health Survey. Journal of Affective Disorders, 2017b; 208: 545-552. 
RESUMO SIMPLES: Revisão Bibliográfica

\section{OS CRITÉRIOS DE INDICAÇÃO E AS COMPLICAÇÕES DA TIREOIDECTOMIA ENDOSCÓPICA TRANSORAL}

Autor/coautores: Clineu Gaspar Hernandes Júnior, Daniela Batista, Fernando Onorato, Isabela Oliveira Eugenio, Lara Calhau Rebouças.

Instituição: União Educacional do Vale do Aço (UNIVAÇO), Ipatinga - MG.

Palavras-chave: Tireoidectomia, Complicações, Transoral.

\section{INTRODUÇÃO}

A cirurgia da glândula tireóide representa o procedimento cirúrgico mais frequente no ramo da Cirurgia de Cabeça e Pescoço. Os crescentes casos de doenças desta glândula, inclusive em pacientes jovens, fomentaram o desenvolvimento de abordagens esteticamente mais favoráveis e seguras (MENDERICO GM, et al., 2021). O desenvolvimento da Tireoidectomia Endoscópica Transluminal por Orifícios Naturais (NOTES) permitiu que a técnica Transoral ganhasse destaque por evitar a formação de cicatrizes cutâneas visíveis. Duas técnicas foram descritas: a sublingual e a Tireoidectomia Endoscópica Transoral por Acesso Vestibular (TOETVA), que apresenta resultados encorajadores com complicações mínimas. Este trabalho objetiva apresentar os benefícios e complicações do método TOETVA (MENDERICO GM, et al., 2021).

\section{OBJETIVO}

Revisar a literatura científica com o objetivo de auxiliar os profissionais da área de cirurgia de cabeça e pescoço frente a esse novo método operatório. Visando melhor qualidade acadêmica, além de compartilhar os avanços da comunidade científica.

\section{REVISÃO BIBLIOGRÁFICA}

A tireoidectomia transoral tem se destacado de maneira a ser utilizada por cirurgiões de todas as regiões. A abordagem com insuflação de $\mathrm{CO}_{2}$ é o procedimento de maior escolha até o momento, visto que proporciona baixa morbidade cirúrgica, cosmese pós-operatória e uma melhor recuperação da voz a curto prazo. No entanto, apesar de mais seguro, ainda há complicações como paralisia de prega vocal, hipoparatireoidismo / hipocalcemia, hematoma e seroma assim como os demais métodos de tireoidectomia (TAE K, 2021).

Para que essa cirurgia seja realizada o paciente deve atender critérios como um diâmetro da glândula tireóide estimado ultrassonograficamente (US) de $10 \mathrm{~cm}$, entre outros. Além disso, esse procedimento, vem se difundindo na prática médica devido a facilidade do uso dos materiais, pelo benefício estético e pelo baixo índice de complicações, sendo assim, uma prática operatória promissora (TESSEROLI MAS, et al., 2018).

\section{CONSIDERAÇÕES FINAIS}

Pode-se dizer que a tireoidectomia transoral é o que há de mais moderno dentro da cirurgia da glândula tireóide, que trouxe benefícios para os pacientes, tanto em tempo de recuperação quanto esteticamente, entretanto por ser um procedimento novo, nem todos possuem acesso.

\section{REFERÊNCIAS}


1. MENDERICO GM, et al. Complications of transoral endoscopic thyroidectomy vestibular approach (TOETVA). Revista Do Colegio Brasileiro De Cirurgioes, 2021; 48 : e20202557.

2. TAE K. Complications of Transoral Thyroidectomy: Overview and Update. Clinical and Experimental Otohinolaryngology, 2021; 14(2): 169-178.

3. TESSEROLI MAS, et al. Tireoidectomia endoscópica transoral por acesso vestibular (TOETVA): experiência inicial no Brasil. Revista do colégio brasileiro de cirurgiões, 2018; 45(5): 1-6. 
RESUMO SIMPLES: Revisão Bibliográfica

\section{ENCEFALITE HERPÉTICA: UMA REVISÃO INTEGRATIVA}

Autor/coautores: Paula Moreira Sena, Natália Aparecida Gonçalves, Melissa Araújo Ulhoa Quintão.

Instituição: União Educacional do Vale do Aço (UNIVAÇO), Ipatinga - MG.

Palavras-chave: Herpes, Encefalite, HSV.

\section{INTRODUÇÃO}

Os vírus da herpes simplex (HSV) são de DNA linear de fita dupla pertencentes à família Herpesviridea (BABAEl A, et al., 2021). Grande parte da população está infectada com este vírus, mais conhecido por apresentações na região genital e oral (MANCINI M e VIDAL SM, 2018). Por possuir amplo potencial neurotrópico, se estende desde manifestações mucocutâneas, até infecções graves do sistema nervoso central (CAMPOS EM, et al., 2021). A encefalite herpética (HSE) é uma doença associada à disfunção cerebral focal ou global onde mais de um terço dos pacientes morrem e cerca de 50\% sobrevivem com sequelas neurológicas, apesar do tratamento adequado (JAROLín MJ, et al., 2021).

\section{OBJETIVO}

Revisar a literatura científica acerca da fisiopatologia da encefalite causada por Herpes Simples, entender sua evolução, sinais e sintomas, prognóstico clínico e complicações, bem como descrever o respectivo panorama da infecção.

\section{REVISÃO BIBLIOGRÁFICA}

A apresentação clínica característica da encefalite herpética consiste em febre, convulsões e, frequentemente, déficits neurológicos focais ou generalizados, dependendo da forma clínica apresentada (MANCINI M e VIDAL SM, 2018). O grau de comprometimento e sequelas está diretamente relacionado à rapidez no estabelecimento da terapia antiviral, logo o diagnóstico rápido e a terapia específica precoce é extremamente importante. (JAROLÍN MJ, et al., 2021).

Uma melhor compreensão da patogênese da doença é necessária para melhor desenvolver estratégias contra o HSV, apesar da terapia antiviral disponível, a HSE permanece sendo uma das infecções neurológicas mais destrutivas do SNC (MANCINI M e VIDAL SM, 2018). Na ausência de tratamento, a taxa de mortalidade de pacientes com HSE é de $70 \%$ e a maioria dos sobreviventes sofre de comprometimento neurológico. Dessa forma, o diagnóstico preciso, sensível e confiável é crucial (BABAEl A, et al., 2021).

\section{CONSIDERAÇÕES FINAIS}

Com base na presente revisão, a encefalite herpética tem como apresentação a tríade clássica febre, cefaléia e alterações de comportamento. O diagnóstico e tratamento da encefalite herpética deve ser precoce, proporcionando redução na taxa de morbidade e mortalidade desta doença.

\section{REFERÊNCIAS}

1. BABAEI A, et al. Prevalence and clinical manifestations of herpes simplex virus infection among suspected patients of herpes simplex encephalitis in Shiraz, Iran. VirusDisease, 2021; 32: 1-8.

2. CAMPOS EM, et al. Dementia and cognitive impairment in adults as sequels of HSV-1-related encephalitis: a review. Dement Neuropsychol, 2021; 15(2): 164-172. 
4. JAROLÍN MJ, et al. Meningoencefalitis herpética en mujer adulta. Revista Virtual de la Sociedad Paraguaya de Medicina Interna, 2018; 5(1): 83-86

5. MANCINI M, VIDAL SM. Insights into the pathogenesis of herpes simplex encephalitis from mouse models. Mammalian Genome, 2018; 29: 425-445. 
RESUMO SIMPLES: Revisão Bibliográfica

\section{DIETA CETOGÊNICA COMO TRATAMENTO PARA EPILEPSIA RESISTENTE A MEDICAMENTOS: UMA REVISÃO DE LITERATURA}

Autor/coautores: Thalita Maria Coelho Cherobim Garonci, Ayla Nazareth Cunha Mascarenhas Lomanto,' Mariana Santos Nascimento Silva, Catarina Amorim Baccarini Pires.

Instituição: União Educacional do Vale do Aço (UNIVAÇO), Ipatinga - MG.

Palavras-chave: Epilepsia, Dieta Cetogênica, Crises epilépticas resistentes.

\section{INTRODUÇÃO}

Epilepsia é um distúrbio contínuo da função cerebral, sendo a doença neurológica crônica mais predominante na pediatria. O tratamento farmacológico é satisfatório na maioria dos casos, contudo, aproximadamente $33 \%$ dos pacientes continuam tendo crises, caracterizando-se como epilepsia resistente a medicamentos (CASTRO F e HERESI C, 2020). Uma opção para o tratamento adjunto é a dieta cetogênica, rica em gorduras, adequada em proteínas e pobre em carboidratos. O mecanismo de ação ainda é obscuro, mas sabe-se que compreende mudanças na função mitocondrial, impacto dos corpos cetônicos na função neuronal e liberação de neurotransmissores, efeitos antiepilépticos de ácidos graxos e/ou estabilização da glicose (SAMPAIO LPB, 2016).

\section{OBJETIVO}

Revisar a literatura científica visando abordar o uso de dietas cetogênicas para o tratamento de epilepsia resistente aos medicamentos em pacientes pediátricos, demonstrando os achados mais relevantes e os principais benefícios.

\section{REVISÃO BIBLIOGRÁFICA}

A dieta cetogênica é uma forma de alimentação com alto teor de ácidos graxos e lipídeos, baixo teor de carboidratos e moderado de proteínas. Essa dieta simula um jejum e os corpos cetônicos chegam ao Sistema Nervoso Central agindo com neuroprotetores e estabilizadores de humor. (CASTRO F e HERESI C, 2020). Estudos observaram nos pacientes pediátricos com epilepsia resistente um controle completo das crises na maioria deles e redução da frequência em quase totalidade, após a dieta. (CASTRO F e HERESI C, 2020).

Outro estudo demonstrou que crianças que recebem a dieta podem aliviar as crises 3 vezes mais e reduzir mais da metade das frequências, comparado a crianças em uso de medicamentos e cuidados habituais. (MARTIN-MCGILL KJ, et al., 2020). Ademais, pesquisas mostraram que a maioria dos cuidadores referiram melhoras comportamentais, de alerta, atenção, qualidade do sono, memória e interação social nas crianças que usaram a dieta cetogênica. (GARCIA-PENAS JJ, 2018).

\section{CONSIDERAÇÕES FINAIS}

De acordo com os dados observados nessa revisão, a dieta cetogênica é considerada uma eficaz terapêutica para controle da epilepsia resistente e vem sendo cada vez mais utilizada, melhorando a qualidade de vida das crianças. Mesmo com resultados favoráveis, são necessários mais estudos para elucidar melhor seus mecanismos e efeitos.

\section{REFERÊNCIAS}


1. CASTRO VF, HERESI VC. Ketogenic diet for refractory childhood epilepsy. Revista chilena de pediatria, 2020; 91(5): 0370-4106.

2. GARCÍA-PEÑAS JJ. Epilepsia, cognición y dieta cetogénica. Revista de neurologia, 2018; 66(01): 29516456.

3. MARTIN-MCGILL KJ, et al. Ketogenic diets for drug-resistant epilepsy. The Cochrane database of systematic reviews, 2020; 6(6): 1903.

4. SAMPAIO LPB. Ketogenic diet for epilepsy treatment. Arquivos de Neuro-Psiquiatria, 2016; 74(10): 16784227. 


\section{| RELATO DE EXPERIÊNCIA}

RESUMO SIMPLES: Relato de Experiência

\section{A DISSEMINAÇÃO DE CONHECIMENTO INTERNACIONAL AO CORPO ACADÊMICO EM PARCERIA COM A LIGA DE INGLÊS MÉDICO: UM RELATO DE EXPERIÊNCIA}

Autores/Coautores: Ana Carolina Da Silva Corrêa, Larissa Dutra Lima, Luiza Rocha Arêdes, Melissa Araújo Ulhoa Quintão.

Instituição: União Educacional do Vale do Aço (UNIVAÇO), Ipatinga - MG.

Palavras-chave: Internacionalização, Inglês, Intercâmbio.

\section{INTRODUÇÃO}

A globalização, seguida da revolução técnico-científica, trouxe desafios aos indivíduos, que precisaram se adaptar ao meio, seja no âmbito acadêmico ou pessoal, buscando novas fontes de informação, partindo para um intercâmbio de pessoas e conhecimento (HABOWSKI AC, et al., 2021; MOROSINI MCN e MACHADO L, 2017). Assim, criado em 2020 o Núcleo de Inovação, Empreendedorismo, Mobilidade Acadêmica e Internacionalização (NIEMAI), que em conjunto com a Liga Acadêmica de Inglês Médico (LIME) da UNIVAÇO, objetiva conceber novas oportunidades ao seu corpo discente e aos diversos agentes do processo educacional, uma vez que a ciência não pode ser feita apenas com ações pontuais, garantindo ensino internacionalizado (LEOPOLDO JFA, et al., 2019).

\section{OBJETIVO}

Apresentar um relato de experiência sobre as ações da LIME em parceria com o NIEMAI da UNIVAÇO e sua importância na construção e consolidação no aprendizado do inglês médico.

\section{RELATO DE EXPERIÊNCIA}

O NIEMAI busca garantir um ensino internacionalizado aos discentes, aproximando o conhecimento global da comunidade acadêmica, aperfeiçoando o ensinamento, a pesquisa e a extensão através de parcerias advindas de outros países. Com isso, em associação com as Ligas Acadêmicas, especialmente a LIME, foi realizada uma Live sobre a internacionalização médica e como validar o diploma no exterior, com o Dr. Marcos Santana - que contou com 242 expectadores, e expôs temas de grande valia e amplamente relacionados com os objetivos da LIME, como os passos para conseguir validação do diploma, a gestão da carreira médica no âmbito internacional e o processo de aprendizagem em um novo país.

Em outra ocasião, foi ministrada uma palestra relacionada à importância do Test of English as a Foreign Language (TOEFL) no currículo médico, evidenciando o papel da internacionalização do conhecimento para o crescimento e melhor desempenho acadêmico dos discentes, seja para pontuar para as residências ou para outros programas de ingresso. Por fim, as lives obtiveram feedback positivo dos alunos, ao esclarecer as dúvidas e orientá-los quanto às decisões futuras.

\section{CONSIDERAÇÕES FINAIS}

Em virtude dos fatos mencionados fica evidente que a parceria estabelecida entre o NIEMAI e a LIME possui um grande potencial promotor do inglês médico no meio acadêmico, auxiliando não só os ligantes, 
como também a comunidade acadêmica a construir um currículo diferenciado com qualificações internacionais.

\section{REFERÊNCIAS}

1. HABOWSKI AC, et al. As juventudes e as tecnologias: horizontes educacionais. Revista IberoAmericana de Estudos em Educação, 2021; 16(2): 440-466.

2. LEOPOLDO JFA, et al. Caminhos da internacionalização dos periódicos de saúde coletiva. Saúde em Debate, 2019; 43(122): 875-882.

3. MOROSINI MCN, MACHADO L., Internacionalização da educação superior no BRASIL: a produção recente em teses e dissertações. Educação em Revista, 2017; 33: e155071. 
RESUMO SIMPLES: Relato de Experiência

\section{IMPLANTAÇÃO DE UM APLICATIVO PARA MONITORAMENTO E BARREIRA SANITÁRIA PARA COVID-19: UM RELATO DE EXPERIÊNCIA}

Autor/coautores: Livia Pêpe Leão da Rocha, Ana Letícia Mendonça de Oliveira, Daniel Guedes de Oliveira, Laura Rodrigues Silva, Melissa Araújo Ulhôa Quintão.

Instituição: União Educacional do Vale do Aço (UNIVAÇO), Ipatinga - MG.

Palavras-chave: COVID-19, Instituição, Aplicativo.

\section{INTRODUÇÃO}

Além das medidas de segurança contra o novo Coronavírus estabelecidas pelo Ministério da Saúde (BRASIL, 2021), uma Instituição de Ensino criou um método de triagem na forma de aplicativo para quem adentra a instituição, sendo constituído de questões concisas e respostas curtas que demandam no máximo 20 segundos para responder. Desta forma, tal método é importante para identificar aqueles com suspeita de COVID-19, auxiliar na redução da transmissão do vírus, proteger a saúde dos alunos e colaboradores e demonstrar como a interação digital está associada às estratégias de enfrentamento pois a doença ainda é uma emergência de saúde global (MOTA DCB, et al., 2021; DI WU, et al., 2020).

\section{OBJETIVO}

Descrever a experiência de um questionário realizado em uma instituição de ensino do Leste Mineiro como estratégia para minimizar a propagação do coronavírus entre os estudantes, colaboradores e visitantes.

\section{RELATO DE EXPERIÊNCIA}

Trata-se de um relato de experiência sobre elaboração de um questionário para minimizar a transmissão do coronavírus em uma instituição de ensino do Leste de Minas Gerais. Ele foi desenvolvido em junho de 2020 pela comissão de enfrentamento à COVID-19 da instituição inspirado no protocolo chinês de retorno às aulas. Todos aqueles que desejassem ter acesso à instituição: alunos, colaboradores ou visitantes, eram dirigidos ao questionário. $\mathrm{O}$ acesso era realizado por link, QRCode ou manualmente (folha impressa).

A avaliação era composta por perguntas de um a nove cuja resposta poderia ser sim ou não. Resultando em: acesso negado ou liberado. Para acesso liberado era necessário que as perguntas 1, 7 e 9 tivessem resposta "sim" e as perguntas 2,3,4,5,6 e 8 "não". Para quaisquer outras combinações o acesso era negado e o visitante orientado pelo segurança sobre isolamento social e auxílio médico. Se acesso liberado, submetiase à aferição de temperatura. $O$ aplicativo foi bem aceito pelos alunos pois além de ser uma excelente forma de triagem, demonstra também zelo com quem adentra ou depende da instituição.

\section{CONSIDERAÇÕES FINAIS}

Portanto, a fim de oferecer mais segurança e efetividade à instituição, o aplicativo é muito bem aceito e elogiado por todos que o utilizam, garantindo uma boa triagem que ajuda a prevenir contra a COVID-19 e à promoção da saúde, contribuindo com ações para a retomada segura das atividades no âmbito social.

\section{REFERÊNCIAS}


1. BRASIL. Manual do Ministério da Saúde. Protocolo de Tratamento do novo Coronavírus (2019-nCoV). 2020. Disponível em https://portalarquivos2.saude.gov.br/images/pdf/2020/fevereiro/05/Protocolo-demanejo-clinico-para-o-novo-coronavirus-2019-ncov.pdf. Acessado em: 10 de julho de 2021

2. DI WU, et al. The SARS-Cov-2 outbreak: What we know. International Journal of Infectious Diseases, 2020; 94: 44-48

4. MOTA DCB, et al. Mental health and internet use by university students: coping strategies in the context of COVID-19. Ciência\&SaúdeColetiva, 2021; 26(6): 2159-2170. 


\section{AGRADECIMENTOS}
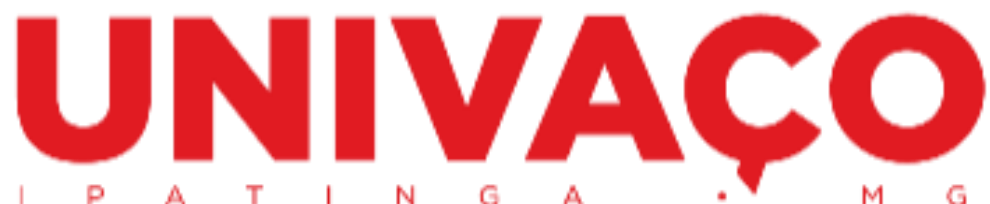

M

Afre 